\title{
Adult Neurogenesis in Fish
}

\author{
Julia Ganz ${ }^{1}$ and Michael Brand ${ }^{2}$ \\ ${ }^{1}$ Institute of Neuroscience, 1254 University of Oregon, Eugene, Oregon 97403 \\ ${ }^{2}$ Biotechnology Center, and DFG-Research Center for Regenerative Therapies Dresden, \\ Technische Universität Dresden, 01307 Dresden, Germany \\ Correspondence: ganz@uoneuro.uoregon.edu,michael.brand@biotec.tu-dresden.de
}

\begin{abstract}
Teleost fish have a remarkable neurogenic and regenerative capacity in the adult throughout the rostrocaudal axis of the brain. The distribution of proliferation zones shows a remarkable conservation, even in distantly related teleost species, suggesting a common teleost ground plan of proliferation zones. There are different progenitor populations in the neurogenic niches_-progenitors positive for radial glial markers (dorsal telencephalon, hypothalamus) and progenitors with neuroepithelial-like characteristics (ventral telencephalon, optic tectum, cerebellum). Definition of these progenitors has allowed studying their role in normal growth of the adult brain, but also when challenged following a lesion. From these studies, important roles have emerged for intrinsic mechanisms and extrinsic signals controlling the activation of adult neurogenesis that enable regeneration of the adult brain to occur, opening up new perspectives on rekindling regeneration also in the context of the mammalian brain.
\end{abstract}

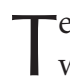
eleost fish display the most prominent and widespread adult neurogenesis throughout the central nervous system compared with any other vertebrate studied so far (Zupanc and Horschke 1995; Zikopoulos et al. 2000; Lema et al. 2005; Zupanc et al. 2005; Adolf et al. 2006; Grandel et al. 2006; Lindsey and Tropepe 2006; Pellegrini et al. 2007; Kaslin et al. 2008, 2009; Alunni et al. 2010; Kuroyanagi et al. 2010; Strobl-Mazzulla et al. 2010; Fernandez et al. 2011; Maruska et al. 2012; Teles et al. 2012; Tozzini et al. 2012; Olivera-Pasilio et al. 2014). Usually, the term adult refers to specimens that have reached their sexual maturity. Twelve to sixteen proliferation zones have been identified along the rostrocaudal axis in different teleosts (Fig. 1) (Zupanc and Horschke 1995; Ekstrom et al.
2001; Grandel et al. 2006; Maruska et al. 2012). Interestingly, the distribution of proliferation zones shows a remarkable conservation between even very distantly related teleost species (e.g., zebrafish and stickleback; Fig. 1B), although there are some species-specific differences in the proliferation pattern, for example, the massive proliferation in the granular eminence of the brown ghost knifefish (Fig. 1B) (Zupanc and Horschke 1995). This remarkable conservation suggests a common teleost ground plan of proliferation zones in the adult brain. Unfortunately, there is no data on proliferation or adult neurogenesis available on more basal teleosts like Osteoglossomorpha (i.e., bony tongues and mooneyes) or Elopomorpha (i.e., eel) nor in rayfin fish species outside the teleost

Editors: Fred H. Gage, Gerd Kempermann, and Hongjun Song

Additional Perspectives on Neurogenesis available at www.cshperspectives.org

Copyright (C) 2016 Cold Spring Harbor Laboratory Press; all rights reserved

Advanced Online Article. Cite this article as Cold Spring Harb Perspect Biol doi: 10.1101/cshperspect.a019018 
J. Ganz and M. Brand

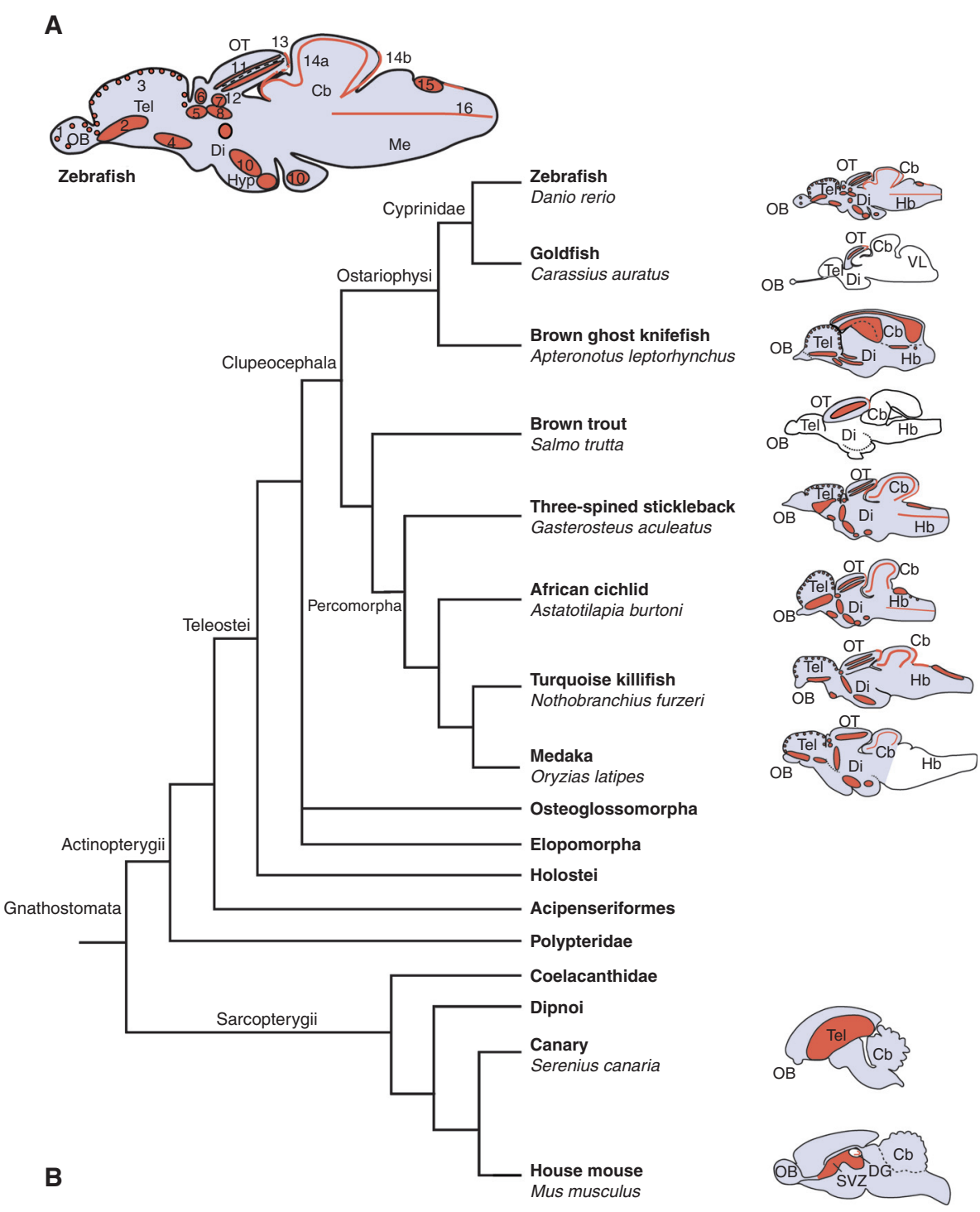

Figure 1. The layout of proliferation zones is conserved among teleost fishes. (A) Proliferation zones in the adult zebrafish brain. (B) Phylogenetic tree of gnathostomata, with sagittal views of brains from different teleost species and the identified proliferation zones (Raymond and Easter 1983; Zupanc and Horschke 1995; Ekstrom et al. 2001; Candal et al. 2005; Grandel et al. 2006; Kuroyanagi et al. 2010; Maruska et al. 2012). White brain regions have not been analyzed with regard to adult proliferation. As a comparison, the proliferation zones in the adult brain of the canary and the house mouse are also shown (Kaslin et al. 2008). (Panel $A$ from Grandel et al. 2006; modified, with permission, from the authors.)

lineage like Lepisosteidae or Polypteridae (i.e., bichir) to determine whether the ground plan of proliferation zones is teleost- or rayfin-specific. It still remains unclear why teleost fish have such a remarkable neurogenic potential in the adult, but two roles of adult neurogenesis have been proposed: (1) addition of neuronscorresponding to brain growth, and (2) replacement and thus turnover of neurons within the brain. It is well known that fish show lifelong growth (Brandstätter and Kotrschal 1989, 1990; Zupanc and Horschke 1995; Nieuwenhuys et al. 
1998), and it has been suggested that the widespread neurogenic capacity throughout the brain is required to expand the existing sensory systems concomitantly with body growth and the accompanying increase in primary sensory input (Kaslin et al. 2008). However, how neurogenesis progresses during the lifetime of the organism, which neuronal subtypes are added or replaced at different stages, and whether indeed all neurons are generated throughout the lifetime remains largely unknown in teleost fish. A recent study showed in detail which neurons are generated in the zebrafish cerebellum from embryo to adulthood (Kaslin et al. 2013). Surprisingly, only granule cells continue to be produced in the adult, whereas Purkinje neurons and eurodendroid cells are only produced up to 1 month and only a few interneurons and glia cells are generated after 3 months (Kaslin et al. 2013). This is interesting because it shows that not all cell types continue to be generated in high numbers in the adult fish brain. In addition, in the zebrafish telencephalon, the number of progenitors and the rate of neurogenesis and oligodendrogenesis are also thought to decrease with age (Edelmann et al. 2013), but it is unknown which neuronal subtypes are generated from larval to adult stages. In contrast, Apteronotus leptorhynchus - which shows linear increase in brain weight and total number of brain cells with body length throughout life-does not show age-related changes in adult neurogenesis (Zupanc and Horschke 1995; Traniello et al. 2014).

Better understanding of adult neurogenesis in teleosts is likely to be informative with respect to reactivating adult neurogenesis in mammalian species, in which this process appears normally to be limited to only two subdivisions of the telencephalon, the dentate gyrus and the subventricular zone (see other articles in the literature). Additional "nonclassical" neurogenic niches in other parts of the mammalian brain, such as in the hypothalamus, have been described, but it remains to be seen whether they show robust, continuous neurogenesis in the adult (Maggi et al. 2014; RojczykGolebiewska et al. 2014). The astounding regenerative capacity of adult zebrafish has recently been reviewed elsewhere (Kizil et al. 2012b; Grandel and Brand 2013; Kyritsis et al. 2014; Becker and Becker 2015). Key concepts that have emerged are, for instance, the dependence of adult neurogenesis during telencephalon regeneration following a stab wound lesion on adult radial glia cells in the absence of scar tissue formation (Kroehne et al. 2011; Kroehne and Brand 2012) and the discovery of a positive stimulatory role of the innate immune system onto regeneration in this process (Kizil et al. 2012c; Kyritsis et al. 2012, 2014). These findings required technological advances, such as the establishment of conditional CreERT2-loxP technology to allow genetic lineage tracing (Hans et al. 2009, 2011; Jungke et al. 2013) or fluorescence-activated cell sorting (FACS) of identified adult radial glia stem cells to identify key changes in their transcriptome (Kizil et al. 2012a; Kyritsis et al. 2012).

A more detailed anatomical understanding, in particular of the structure of the adult stem cell niche and the involved cell types in constitutive and regenerative neurogenesis is warranted, and is reviewed below. In mammals, it is well established-and was a surprising discoverythat progenitors in the adult brain show glial characteristics. In teleost, progenitors with radial glia characteristics are also present the adult brain, such as in the dorsal telencephalon and the hypothalamus. Surprisingly, most of the studied neurogenic niches contain progenitors with neuroepithelial-like characteristics, such as the ventral telencephalon, optic tectum, and the cerebellum. In addition, a second glial-markernegative progenitor population has been identified in the dorsal telencephalon, whose cellular nature remains unknown (Ganz et al. 2010). In the next sections, we will present five wellstudied neurogenic niches at different rostrocaudal levels of the teleost brain.

\section{DISTINCT PROGENITOR NICHES IN THE DORSAL AND VENTRAL TELENCEPHALON: CELL TYPES AND DIFFERENTIATION PATTERN}

The telencephalon is the rostralmost part of the brain and can be subdivided in a dorsal part 
(pallium) and a ventral part (subpallium) (Nieuwenhuys et al. 1998). In contrast to all other vertebrates, the telencephalon of rayfin fishes does not undergo a morphogenetic process called evagination but instead forms by eversion (Nieuwenhuys 2009). This leads to a unique telencephalic morphology with an unpaired ventricle covering most of the surface of the telencephalon (Nieuwenhuys and Meek 1990; Northcutt 1995; Nieuwenhuys 2009). In zebrafish, careful in vivo imaging showed that the morphogenetic movement does not comprise a simple lateral outward bending, but a two-step process. First, the ventricle between telencephalon and diencephalon folds outward, and subsequently, the pallial area expands rostrally (Folgueira et al. 2012). This difference in development results in a different arrangement of pallial parts compared with all other vertebrates (Northcutt 1995; Nieuwenhuys 2009). Several models of the homology of areas in the pallium of rayfin fishes with nuclei in the pallium of tetrapods have been proposed based on connectional, neurochemical gene expression and functional data. Ablation experiments and conserved marker gene expression suggests that the lateral nucleus of the dorsal telencephalon is homologous to the hippocampus-one of the two brain regions in mammals that generate neurons in the adult (Rodriguez et al. 2002a,b; Broglio et al. 2010; Duran et al. 2010; Ganz et al. 2014). Based on conserved marker gene expression, it has been proposed that the ventral telencephalon is subdivided rostrally into striatum and septum and at midtelencephalic levels into striatum, pallidum, and septum (Ganz et al. 2012). In the zebrafish telencephalon, the neurogenic niches have been described in detail, and it has been shown that the neurogenic niches in the dorsal and ventral telencephalon have distinct characteristics in the distribution and cellular nature of progenitors and mode of neurogenesis (Fig. 2). Interestingly, differences emerge in the distribution of glial markers that correlate with proliferative characteristics, as well as modes of neurogenesis in the respective progenitor zones, which we discuss separately in the following sections.

\section{Ventral Telencephalon}

In teleosts, the ventral telencephalon is subdivided into ventral (ventral nucleus of the ventral telencephalon, $\mathrm{Vv}$ ) and dorsal parts (dorsal nucleus of the ventral telencephalon, Vd). The proliferation zones at the ventricular zone of $\mathrm{Vv}$ and $\mathrm{Vd}$ have distinct characteristics, with $\mathrm{Vd}$ being more similar to proliferation zones in the dorsal telencephalon (Fig. 2D) (Adolf et al. 2006; Grandel et al. 2006; Lindsey and Tropepe 2006; Ganz et al. 2010; Marz et al. 2010a; Lindsey et al. 2012). In the ventricular zone of $\mathrm{Vv}$, proliferating cells are present in a large domain at the ventricle composed of tightly packed proliferating cells. More caudally, the proliferation zone then shifts dorsally and reduces in size to a small stripe of proliferating cells (Fig. 2F) (Grandel et al. 2006; Ganz et al. 2010; Lindsey et al. 2012). The progenitors of $\mathrm{Vv}$ have neuroepithelial-like features, such as apicobasal polarity and interkinetic nuclear migration (Fig. 2D) (Ganz et al. 2010; Lindsey et al. 2012). They lack the expression of typical radial glial markers, but express nestin (Ganz et al. 2010; Marz et al. 2010a; Lindsey et al. 2012). PSA-NCAM expression in the lateral part of the proliferation zone suggests that neuronal precursors are located there (Fig. 2D) (Adolf et al. 2006; Marz et al. 2010a; Kishimoto et al. 2011). At midtelencephalic levels, proliferating cells in the ventral part of $\mathrm{Vv}$ are positive for olig2:EGFP, an oligodendrocyte/oligodendrocyte precursor marker (Fig. 2F) (Marz et al. 2010b). Cells positive for olig2:EGFP and PSA-NCAM are found in close proximity to the ventricular proliferation zone suggesting that these might be oligodendrocyte precursors migrating into the parenchyme (Marz et al. 2010b). In Vd, proliferating cells are scattered along the ventricle and express markers of typical radial glia cells (Ganz et al. 2010; Marz et al. 2010a; Lindsey et al. 2012). Bromodeoxyuridine (BrdU) pulse-chase experiments show that label-retaining actively cycling cells (LRCs), which have been suggested to be candidate stem cells, are present in the ventricular zone of $\mathrm{Vv}$ and $\mathrm{Vd}$ (Adolf et al. 2006; Grandel et al. 2006; Ganz et al. 2010; Marz et al. 2010a). In the rostral Vv, LRCs oc- 
A

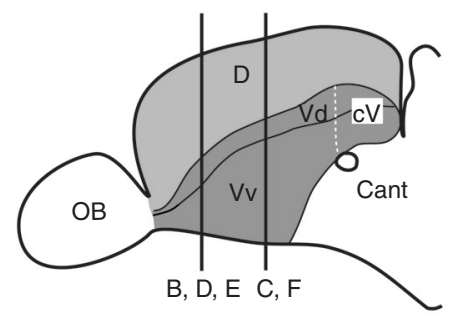

B

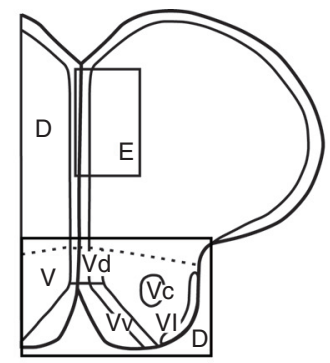

D

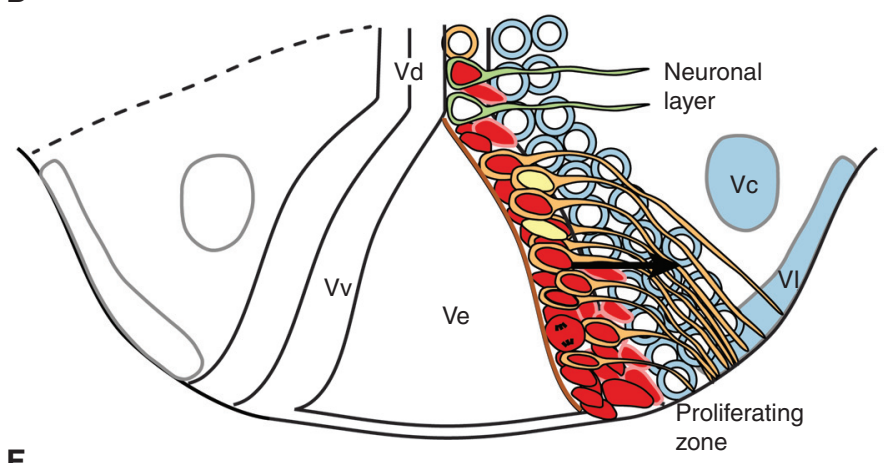

$\mathbf{F}$

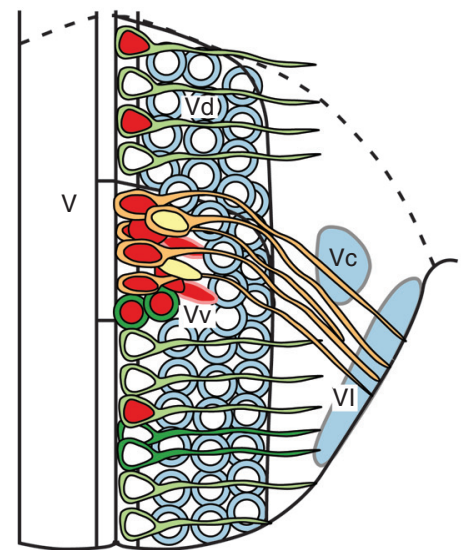

\section{- Apical marker+}

C

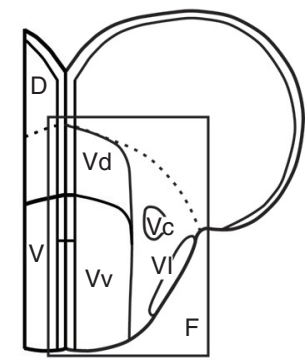

E

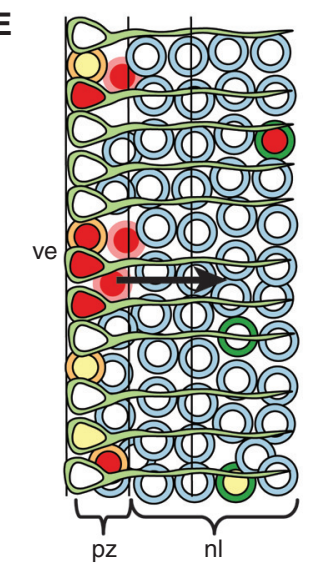

Glial marker+

Glial marker-

Olig2: GFP+

PSA-NCAM+

Neuronal layer

Figure 2. The neurogenic niches in the ventral and dorsal telencephalon have distinct characteristics. (A) Sagittal view of the telencephalon. The levels of cross sections in panels $B-F$ are indicated. $(B, C)$ Cross-sections of the telencephalon at rostral $(B)$ and midtelencephalic levels $(C) .(D, F)$ Characteristics of the neurogenic niche in the ventral telencephalon at rostral $(D)$ and midtelencephalic levels $(F)$. $(E)$ Characteristics of the neurogenic niche in the dorsal telencephalon. The dashed line indicates the border between the ventral and dorsal telencephalon. Ve, Ventricle; pz, proliferation zone; nl, neuronal layer. (Panels $D-F$ from Ganz et al. 2010; modified, with permission, from the authors.)

cupy a preferential position in the dorsal half of the progenitor zone, whereas in the caudal part of Vv, LRCs distribute evenly along the dorsoventral axis (Ganz et al. 2010). These slowlycycling LRCs in Vv are mainly negative for nestin:GFP, suggesting that the majority of nes-
tin:GFP positive cells belong to the fast-cycling population of progenitors in $\mathrm{Vv}$ ( Ganz et al. 2010).

Neurogenesis in the ventral telencephalon contributes both to the different nuclei of the ventral telencephalon and to the olfactory bulb 
(Adolf et al. 2006; Grandel et al. 2006; Kishimoto et al. 2011). Consistent with in vivo CreloxP mediated lineage-tracing data of adult radial glia (Kroehne et al. 2011), viral infection assays have yielded green fluorescent protein (GFP)-labeled new neurons. These new neurons can be detected after $1 \mathrm{wk}$ in the neuronal layer next to the ventricular zone (VZ) and $2 \mathrm{wk}$ after infection; the majority of GFP-positive cells are found in the neuronal layer (Rothenaigner et al. 2011). In zebrafish, in vivo imaging of hemisphere cultures show that precursors migrate tangentially from the rostroventral telencephalic proliferation zone into the olfactory bulb similar to the mammalian rostral migratory stream (RMS) even though there is no extensive stream of neuronal precursors but rather dispersal of single progenitors into the olfactory bulb (Kishimoto et al. 2011). It remains to be clarified whether progenitors contribute to the olfactory bulb from more caudally located points in the ventral telencephalic proliferation zones. In contrast to the RMS, neuronal precursors do not migrate within glial tubes, but close to blood vessels, which might serve as scaffolds (Kishimoto et al. 2011). It remains unclear whether the proliferation zones of $\mathrm{Vv}$ and $\mathrm{Vd}$ contain homogenous progenitor populations or different levels along the proliferation zone give rise to different neuronal subtypes or contribute to different neuronal nuclei. In mouse embryonic and adult subpallium, distinct transcription factor expression profiles are present, and these progenitor zones give rise to different neuronal subtypes (Puelles et al. 2000; Guillemot 2005; Flames et al. 2007; Alvarez-Buylla et al. 2008). In zebrafish, differential expression of conserved molecular marker genes like $d l x 2 a$, $d l x 5 a$, gad67, and $n k x 2.1 b$ subdivide the ventral telencephalon into striatum, pallidum, and septum (Mueller and Guo 2009; Ganz et al. 2012). These genes play a role in generating different neuronal subtypes and are expressed from the embryo to the adult suggesting that the progenitors zones of the ventral telencephalon might give rise to different neuronal subtypes as well (Zerucha and Ekker 2000; Hauptmann et al. 2002; Mueller et al. 2008; Ganz et al. 2012). Detailed lineage-tracing experiments with telencephalic subdomain-specific lines of progenitors and their offspring are necessary to identify which neuronal progenitors in $\mathrm{Vv}_{\mathrm{V}}$ and Vd generate which neuronal subtypes and what their migration routes are within the ventral telencephalic nuclei and the olfactory bulb.

\section{Dorsal Telencephalon}

The progenitor zone of the dorsal telencephalon consists of small clusters of proliferating cells scattered along the whole ventricular surface (Adolf et al. 2006; Grandel et al. 2006; Ganz et al. 2010). In the dorsal telencephalon, two populations of progenitor cells have been identified. One population expresses typical markers of radial glia cells (GFAP, S100b, vimentin, glutamine synthetase [GS], aromatase B [Aro-B]), the other population lacks expression of typical glial markers (Pellegrini et al. 2007; Lam et al. 2009; Ganz et al. 2010; Marz et al. 2010a). There are clusters of PSA-NCAM-positive cells present in the dorsal progenitor domain, and it has been suggested that the glial-marker-negative population comprises intermediate progenitors (Marz et al. 2010a). Lineage-tracing studies using the Cre/loxP system has shown that a subpopulation of her4.1 radial glia gives rise to neurons in the dorsal telencephalon (Kroehne et al. 2011). Clonal analysis with viral vectors suggests that a population of radial glia cells undergoes slow symmetric gliogenic divisions, which can be self-renewing (Rothenaigner et al. 2011). The analysis also showed the presence of bipotent-neurogenic and gliogenic_-progenitors and suggested that there is only a small transient-amplifying population of progenitors in the dorsal telencephalon (Rothenaigner et al. 2011). BrdU pulse-chase experiments showed that, after a 6-wk chase, the number of glial-marker-negative, active cycling, and label-retaining cells is a lot higher compared with the glial-marker-positive LRC population (Ganz et al. 2010). The glial-marker-negative LRC population does not express olig2:GFP, a marker for oligodendrocyte progenitors and oligodendrocytes, even though a small population of olig2:GFP-positive proliferating 
cells and LRCs can be found in the parenchyme (Ganz et al. 2010; Marz et al. 2010a,b). It has been suggested that all glial-marker-negative proliferating cells belong to the transit-amplifying neuronal progenitor population (Chapouton et al. 2010; Marz et al. 2010a). However, the proliferation dynamics of LRCs do not match the dynamics of a transit-amplifying population, which suggests that the glial-marker-negative LRC population is a second progenitor population. The cellular nature of glial-markernegative LRCs and the cell type(s) they generate remain to be determined.

In the dorsal telencephalon, newly generated neurons typically do not migrate far away from the VZ, but stay at a small distance of 1-2 cell diameters from the ventricle (Adolf et al. 2006; Grandel et al. 2006; Kroehne et al. 2011; Rothenaigner et al. 2011). They express mature neuronal markers, have synaptic contacts, and get integrated into the brain circuitry (Adolf et al. 2006; Grandel et al. 2006; Kroehne et al. 2011; Rothenaigner et al. 2011). The extent of neuronal differentiation and which neuronal subtypes continue to be generated in the adult dorsal telencephalon remains unclear. Different transcription factors (ascl1a, eomesa, emx1, and emx3) are expressed in scattered cells in the VZ of the dorsal telencephalon and might be involved in differentiation of neuronal pallial subpopulations (Ganz et al. 2014). It will be interesting to perform subtype-specific Cre/ loxP-based lineage tracing to follow progenitor fate in the dorsal telencephalon.

\section{HYPOTHALAMUS AND THE OPTIC TECTUM: TWO UNIQUE NEUROGENIC NICHES IN THE FISH BRAIN}

\section{Hypothalamus}

In teleosts, the hypothalamus is by far the largest part of the diencephalon and can be subdivided into dorsal, ventral, and caudal parts (Wullimann et al. 1996; Ekstrom et al. 2001; Grandel et al. 2006; Maruska et al. 2012). Proliferating cells are located along the ventricle of the three parts of the hypothalamus and form a contiguous proliferation zone (Fig. 3) (Zupanc and Horschke 1995; Ekstrom et al. 2001; Zupanc et al. 2005; Grandel et al. 2006; Kuroyanagi et al. 2010; Maruska et al. 2012). Around the posterior recess, scattered proliferating cells are found several cell diameters away from the ventricle (Ekstrom et al. 2001; Grandel et al. 2006; Maruska et al. 2012). In zebrafish, cells positive for the glial markers, S100b, GFAP, and Aro-B, line the ventricle except in the ventral hypothalamus, in which S100b is not expressed (Menuet et al. 2005; Grandel et al. 2006; de Oliveira-Carlos et al. 2013). The cellular components of the neurogenic niches in the hypothalamus are not well understood. In the dorsal hypothalamus, two populations of proliferating cells are present, one glial-marker positive and one glialmarker negative (Fig. 3) (Pellegrini et al. 2007; de Oliveira-Carlos et al. 2013), but the distribution of progenitors among those populations is unknown. In BrdU pulse-chase experiments, slowly cycling LRCs have been found in the hypothalamic proliferation zones (Grandel et al. 2006; J Ganz, J Kaslin, and M Brand, unpubl.). Interestingly, LRCs in the dorsal, ventral, and caudal hypothalamus are not positive for the typical glial markers S100, GFAP, or vimentin (Fig. 3) (J Ganz, J Kaslin, and M Brand, unpubl.). In BrdU pulse-chase experiments, most proliferating cells migrate only few cell diameters away from the ventricle into the neuronal nuclei of the ventral hypothalamus and in the dorsal hypothalamus around the lateral recess (Grandel et al. 2006; Maruska et al. 2012). Here, newly generated $\mathrm{TH}^{+}$and $5 \mathrm{HT}^{+}$neurons can be detected (Grandel et al. 2006). In the wall of the posterior recess, however, proliferating cells are intermingled with their progeny (Grandel et al. 2006). It remains to be determined what the specific cellular characteristics of the hypothalamic neurogenic niches are and which cell types are generated in the adult teleost hypothalamus.

\section{Optic Tectum}

The optic tectum is the most prominent structure of the midbrain and is a paired structure located in the dorsal mesencephalon. It receives mainly input from the optic tract and integrates spatial aspects of visual and other sensory input 
J. Ganz and M. Brand
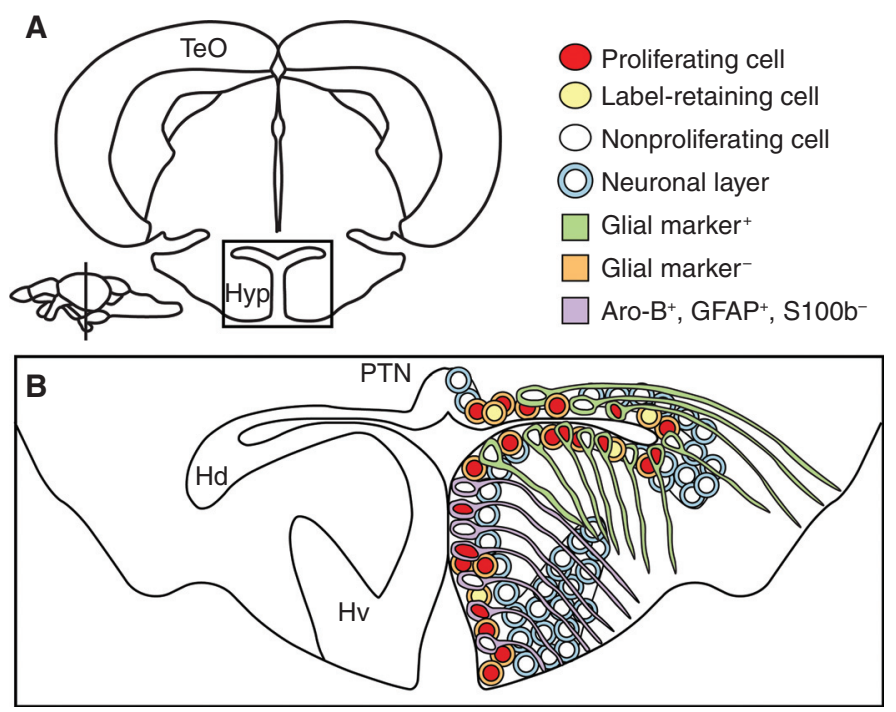

Figure 3. Cellular composition of the neurogenic niche in the hypothalamus. (A) Cross-section of the diencephalon/mesencephalon, boxed area is shown close up in $B$. $(B)$ The neurogenic niche in the hypothalamus.

(Nieuwenhuys et al. 1998). It is well established that, in teleosts, the optic tectum continues to grow throughout the lifetime (Nieuwenhuys et al. 1998). One feature of the tectum is its retinotopic organization (Nieuwenhuys et al. 1998). A second noticeable feature of the optic tectum is its laminar organization: in teleosts, it consists of seven layers. The majority of tectal neurons are tightly packed in layer 1 , the periventricular gray zone (PGZ), the other layers 2 to 7 are often collectively referred to as optic tectum (Meek 1983; Wullimann et al. 1996; Nieuwenhuys et al. 1998). The PGZ also has a layer of GFAP, S100b, and fabp7a-positive radial glia cells, which are located in the deep layer of PGZ along the tectal ventricle (Fig. 4) (Alunni et al. 2010; Ito et al. 2010). In teleosts, proliferating cells are present at the dorsal, ventral, and caudal margins of the optic tectum (Raymond and Easter 1983; Zupanc and Horschke 1995;

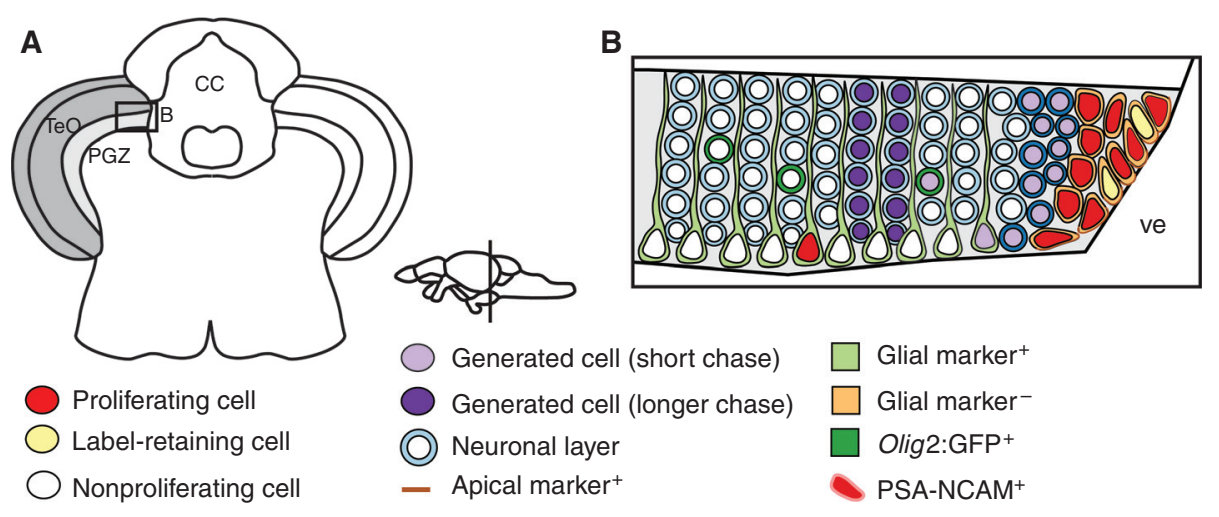

Figure 4. Progenitor characteristics and neurogenesis in the optic tectum. (A) Cross section of the diencephalon/mesencephalon, boxed area is shown close up in $B .(B)$ The neurogenic niche of the periventricular gray zone (PGZ) in the optic tectum. (Panel $B$ generated from data in Ito et al. 2010.) 
Marcus et al. 1999; Nguyen et al. 1999; Ekstrom et al. 2001; Candal et al. 2005; Grandel et al. 2006; Alunni et al. 2010; Ito et al. 2010; Kuroyanagi et al. 2010; Maruska et al. 2012; Teles et al. 2012; Olivera-Pasilio et al. 2014). In zebrafish and medaka, the majority of proliferating cells are located in the caudal part of the PGZ, in which LRCs are concentrated in the dorsomedial part of the optic tectum. They are present in a crescent-shaped zone restricted to the margin of the PGZ (Fig. 4) (Raymond and Easter 1983; Grandel et al. 2006; Ito et al. 2010). There are also few proliferating cells in the PGZ with radial glia characteristics, whose proliferation is enhanced after optic nerve crush (Stevenson and Yoon 1981; Ito et al. 2010).

In zebrafish, the progenitor zone of PGZ contains both slowly cycling label-retaining cells and more rapidly cycling progenitors (Fig. 4) (Raymond and Easter 1983; Grandel et al. 2006; Alunni et al. 2010; Ito et al. 2010). Interestingly, proliferating cells do not show typical radial glia characteristics like expression of GFAP, S100b, fabp7a, or brain lipid-binding protein (BLBP) (Fig. 4) (Grandel et al. 2006; Alunni et al. 2010; Ito et al. 2010). Instead, the progenitor zone displays neuroepithelial-like characteristics on an ultrastructural level (Fig. 4) (Raymond and Easter 1983) and by expression of the apicobasal polarity markers zona occludens-1 (ZO1), $\gamma$-tubulin, and atypical protein kinase C (aPKC) (Fig. 4) (Ito et al. 2010).

In zebrafish, the progenitor zone of the PGZ gives rise to GABAergic and glutamatergic neurons, radial glia cells, and oligodendrocyes (Ito et al. 2010). New neurons are added in a characteristic fashion, in which newly generated cells are displaced laterally (Fig. 4) (Raymond and Easter 1983; Raymond et al. 1983; Nguyen et al. 1999; Grandel et al. 2006). There is no tangential dispersion of generated cells, but they move as a cohort away from the progenitor zone (Fig. 4) (Nguyen et al. 1999; Alunni et al. 2010; Ito et al. 2010). In medaka and zebrafish, it has been observed that newly generated cells can be found in all layers of the optic tectum, even though the majority of newly generated cells stay within the PGZ (Nguyen et al. 1999; Grandel et al. 2006).

\section{CEREBELLUM FROM EMBRYO TO ADULT- CHARACTERISTICS OF A NEUROGENIC NICHE}

Cerebellar development and neurogenesis have enjoyed considerable attention in vertebrates (Altman and Bayer 1997; Wingate 2001), and have recently been characterized in some detail in zebrafish. Because adult neurogenic niches in the zebrafish cerebellum emanate in an orderly fashion from the embryonic sites, the following gives a brief account also of developmental aspects (for details, see Kaslin et al. 2009, 2013; Kaslin and Brand 2012, and references therein).

Cerebellar Progenitors and Germinal Zones

Cerebellar neurons and glia originate from two principal germinal zones in the embryonic hindbrain, the rhombic lip (RL), and the VZ. The VZ consists of the inner germinal zone that is located directly at the fourth ventricle, whereas the RL comprises the dorsal outer germinal zone that is located at the interface of the dorsal neural tube and the roof plate at the rim of the fourth ventricle (Fig. 5) (Wingate 2001). The $\mathrm{RL}$ is further divided into a rostral upper (cerebellar) and a caudal lower (hindbrain) part (Altman and Bayer 1997). In amniotes, granule cell precursors migrate from the upper rhombic lip (URL) to the cerebellar surface, in which they transiently form a highly proliferative second germinal zone, the external granule layer (EGL).

During vertebrate development, different cerebellar cell types are produced in a strict spatial and temporal order from increasingly committed progenitors (Wang and Zoghbi 2001; Carletti and Rossi 2008). Excitatory neurons are generated by the RL, and inhibitory neurons are generated from the VZ (Hoshino et al. 2005). The transcription factor Ptfla marks progenitors of inhibitory neurons in the VZ, whereas the transcription factor Ato1 labels progenitors for excitatory cells in the RL and subsequent EGL (Ben-Arie et al. 1997; Hoshino et al. 2005; Pascual et al. 2007). In chick and rodents, the extracerebellar and cerebellar-long 
J. Ganz and M. Brand

A

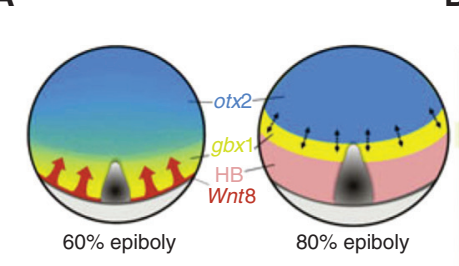

D
B C

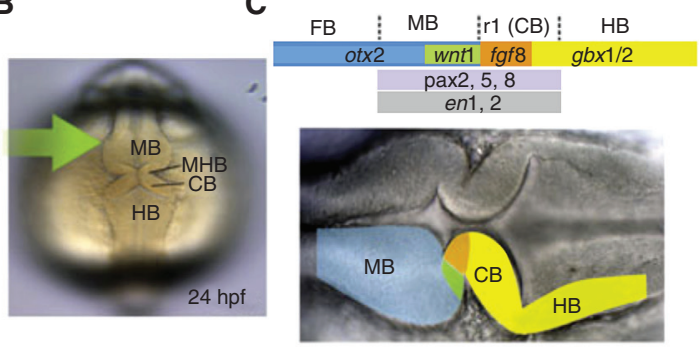

Ventricle start to

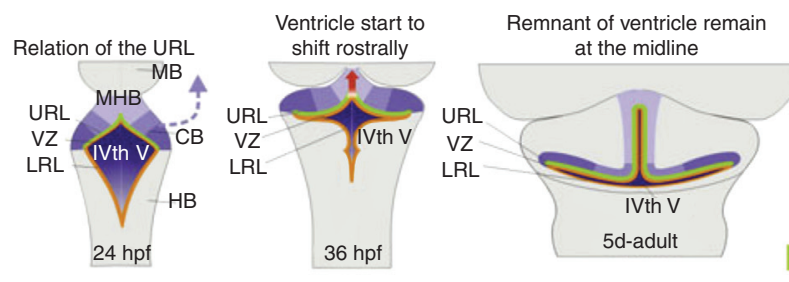

E $\quad 7$ days

CNS growth $\rightarrow$ Adult

URL

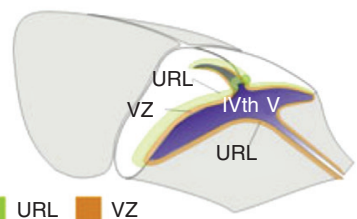

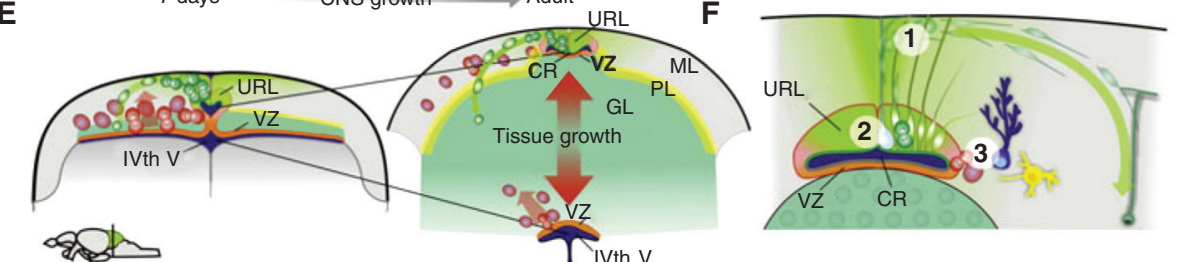

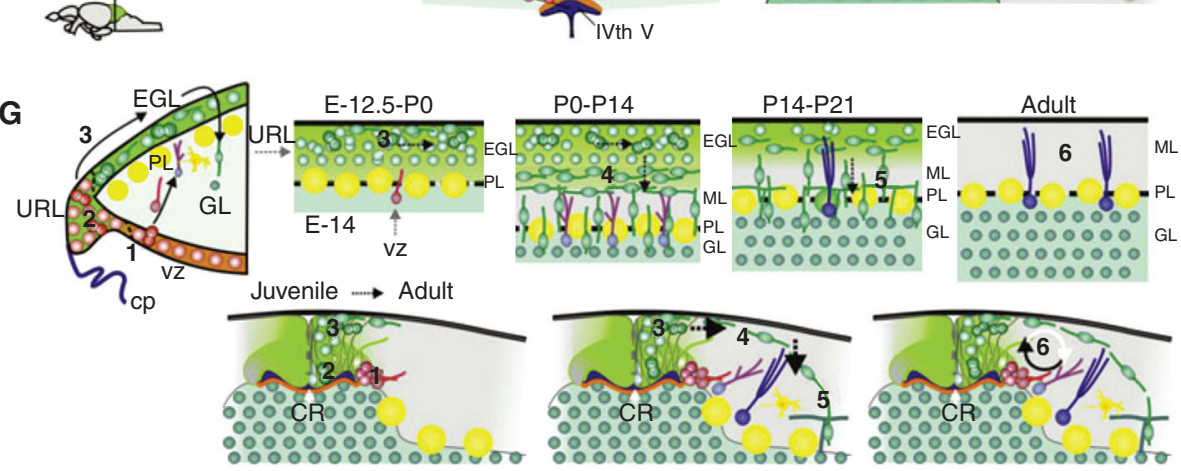

Figure 5. Development and neurogenesis in the cerebellar niche. Cerebellar development in vertebrates depends on $(A)$ the isthmic organizer positioned at the midbrain-hindbrain boundary (MHB) in the neural plate of zebrafish at the interface between otx (blue) and $g b x$ (yellow) expression domains occuring during gastrulation, under control of Wnt8 secreted by the blastoderm margin (red arrows). Gray area 1/4 developing axial mesoderm. Light gray $1 / 4$ yolk. (Panel $A$ modified from data in Rhinn et al. 2005.) $(B, C)$ Morphogenetic events of the cerebellar primordium. At $24 \mathrm{hpf}$, the $\mathrm{MBH}$, midbrain structures, and the cerebellar primordium are clearly distinguishable in the zebrafish embryo. $(C)$ At the end of gastrulation, a complex genetic network with several region-specific transcription factors and the secreted molecules Wnt1 and Fgf8 are expressed at the otx/gbx interface. The secreted signals from the isthmic organizer in turn determine the development of the surrounding mid- and hindbrain tissue. (D) Summary of the early morphogenetic events and the establishment of the progenitor domains. There is a morphogenetic rotation of the cerebellar primordium (blue arrow). From 36 hpf onward, the dorsomedial part of the fourth ventricle is shifted anteriorly creating a dorsomedial extension of the fourth ventricle (red arrow). Ventricularly located progenitors (orange line) are found in the lower rhombic lip (LRL) of the hindbrain and in the ventricular zone (VZ) of the cerebellum. Cerebellar progenitors adjacent to the roof plate are induced to turn into granule cell progenitors (upper rhombic lip [URL] green line). (E) Schematic summary of tissue growth and displacement of the progenitor niche. Displacement of the URL progenitor niche through tissue growth begins $\sim 7 \mathrm{dpf}$. (Legend continues on following page.) 
projecting neurons are produced first, followed by diverse cerebellar interneurons (reviewed in Wang and Zoghbi 2001; Carletti and Rossi 2008). The deep cerebellar nuclei and other extra cerebellar nuclei (precerebellar nuclei) are generated before the genesis of the cerebellar cells in both the VZ and the RL (Hoshino et al. 2005). The generation of cerebellar inhibitory neurons follows an inside-out sequence from deep to superficial layers, in which the VZ generates the long projecting Purkinje neurons, Golgi/Lugaro cells, basket cells, and stellate cells in a temporal succession (Carletti and Rossi 2008). In contrast to VZ, the generation of excitatory neurons from RL follows an outsidein sequence in which unipolar brush cells are generated first, followed by the generation of granule cells (Machold and Fishell 2005; Wang et al. 2005; Englund et al. 2006; Fink et al. 2006).
In zebrafish, the cerebellar primordium becomes morphologically distinguishable during midsegmentation stages (Fig. 5) (Langenberg et al. 2006). Shortly after the formation of the cerebellar primordium, the expression of the neural progenitor markers atohl and ptfla is detected in RL, marking the onset of neurogenesis. The upper and lower RL parts are well recognizable 1 day after fertilization (Fig. 5) and $a$ toh $1 a-b$ expression is detected in the whole RL (Kim et al. 1997; Koster and Fraser 2001; Adolf et al. 2004; Kani et al. 2010), whereas ptfla expression is confined to the LRL (Zecchin et al. 2004; Aldinger and Elsen 2008; Volkmann et al. 2008; Kani et al. 2010). Also at this time, the first cells start migrating out from the RL (see below) (Koster and Fraser 2001). The ptf1a expression is first detected shortly after $36 \mathrm{hpf}$ in the cerebellar plate, in which it is expressed ventricu-

Figure 5. (Continued) During juvenile stages, there is vast generation of granule cells and massive expansion of the granule cell layer. The expanding granule cell layer separates the dorsomedial part of the IVth ventricle and the progenitors in the URL (green) from the rest of the IVth ventricle and the VZ. The addition of axonal fiber mass to the molecular layer further separates the URL progenitors dorsally from the roof plate/meninge. URL progenitors (green) are maintained dorsal to the cerebellar recessus in adult zebrafish, whereas ventricular-zonederived progenitors and glia (orange) are found ventral to the recessus around the IVth ventricle. $(F)$ Schematic summary of the zebrafish cerebellar progenitor niche. Neural progenitors derived from the URL are maintained in the dorsomedial part of the cerebellum around a remnant of the IVth ventricle (the cerebellar recessus). These progenitors give rise to granule neurons in a distinct outside-in fashion. Steps are numbered: (1) Polarized neuroepithelial-like progenitors (green) are restricted to the midline of the dorsal cerebellum. The progenitors give rise to rapidly migrating granule precursors (dark green) that initially migrate dorsolaterally. During this initial phase, the granule precursors still may proliferate. After reaching the meninge, the granule precursors change to a unipolar morphology and migrate in a ventrolateral direction toward the granule layer (GL). The granule precursors migrate into the GL and differentiate into granule neurons. (2) A few glia with a radial morphology (light blue), found close to the midline, are used as scaffolds during the initial dorsal migration of granule precursors. (3) Bergmann glia-like cells are interspersed in the Purkinje cells layer (PL) (dark blue). A low amount of Bergmann glia-like cells and inhibitory neurons (yellow) are generated from VZ progenitors that are found lateral and ventral to the progenitor niche. VZ progenitors are also found ventrally around the IVth ventricle (see $E$ ). $(G)$ Comparison of the life-long maintained neurogenic program in the zebrafish cerebellum and the cerebellar developmental program in mammals. Numbered steps: (1) Ventricularly located VZ progenitors (orange) generate precursors (red) for inhibitory neurons and glia (yellow and blue). (2) In mammals, progenitors (green) in the URL feed the EGL with granule cell precursors. In zebrafish, no distinct EGL is discernable, although precursors do divide en route. (3) In mammals, greatly amplifying granule cell precursors are found in the EGL. The granule cell precursors are initially tangentially migrating. In contrast, a low level of amplification takes place in the zebrafish brain. $(4,5)$ Granule cell precursors become postmitotic, differentiate, and migrate ventrally into the GL. (6) In the mammalian cerebellum, the URL and EGL are exhausted of their progenitors, whereas in zebrafish, primary URL progenitors and some VZ progenitors are maintained in a dividing state by a specialized niche. CB, cerebellar primordium; HB, hindbrain GL, granule cell layer; IVth V, fourth ventricle; LRL, lower rhombic lip; MHB, midbrain-hindbrain boundary; ML, molecular layer; PL, Purkinje cell layer; URL, upper rhombic lip; VZ, ventricular zone; CP, choroid plexus; CR, cerebellar recessus; EGL, external granule layer. (From data in Kaslin and Brand 2012 and Kaslin et al. 2009, 2013; adapted, with permission, from the authors.) 
larly in close proximity to the fourth ventricle. The ptfla expression is abutting a dorsal domain of atoh1 expression (Volkmann et al. 2008; Kani et al. 2010). Thus, at 2 days after fertilization, two distinct adjacent progenitor domains that anatomically and molecularly correspond to the URL and VZ domains of other vertebrates can be detected in the zebrafish cerebellar primordium (Fig. 5).

Spatial patterning of progenitor domains in the embryonic rodent RL corresponds to the functional domains in the mature cerebellum; granule cells that are generated rostrally generally end up medially, whereas granule cells generated caudally end up in a lateral position (Fig. 5) (Sgaier et al. 2005, 2007). Similarly, progenitors from different zones of the URL in zebrafish migrate along distinct paths to the corpus cerebelli, eminentia granularis, and the caudal lobe (CCe, EG, and LCa) (Volkmann et al. 2008; Rieger et al. 2009). Granule cell progenitors in the medial part of the RL produce granule neurons in the corpus cerebelli, whereas progenitors in the lateral part generate granule cells in the eminentia granularis. A stationary population of granule progenitors in the caudal part of the RL produces the granule cells in the caudal lobe (Volkmann et al. 2008). Interestingly, the spatial patterning of progenitors in the RL can be related to distinct gene-expression patterns. During granule cell development, atoh1a expression is confined to the very anterior part of the RL, whereas atoh1c is restricted to the medial and caudal parts of the RL, suggesting that the atoh1 genes are involved in the spatial patterning of the progenitor domains in the RL (Chaplin et al. 2010; Kani et al. 2010). Furthermore, the expression of markers, such as eomesa (tbr2), calbindin2, barhl1.1, and barhl1.2, is different in granule cells in the caudal lobe compared with granule cells in the corpus cerebelli or eminentia granularis (Bae et al. 2009). Taken together, this suggests that distinct gene expression programs control the generation of different granule-cell-progenitor domains and specific migratory patterns in the RL. Consistent with this notion, specific cell types are generated from different domains along the $\mathrm{VZ}$ in rodents (Altman and Bayer 1997).

\section{Cerebellar Neurogenesis}

The initial wave of delamination and migration of cells from the cerebellar primordium (URL) starts 1 day after fertilization (Koster and Fraser 2001), and early migrating cells from the URL end up in tegmental nuclei located below the cerebellum (Kani et al. 2010; Volkmann et al. 2010). Cell migration to the valvula cerebelli and the tegmental nuclei outside the cerebellum was detected during the first 2 days by following atohla:gfp protein perdurance or photoconverted Kaede in cells originating from the rostromedial tip of the URL (Kani et al. 2010). In a complementary fate-mapping approach using the wnt1:gal4-VP16-14 × UAS:GFP transgenic fish line that specifically labels atoh1a expressing cells in the rostromedial part of the URL showed that early migratory cells from the URL contribute to cholinergic and glutamergic neurons of the secondary gustatory/ viscerosensory nucleus, nucleus isthmi, and superior reticular nucleus (Volkmann et al. 2010). Interestingly, the cells in the precerebellar nucleus lateralis valvulae are not derived from wnt1:gal4-VP16-14 × UAS:GFP-positive cells in the URL (Volkmann et al. 2010). A similar rostroventral migratory pathway from the early URL to several different nuclei in tegmentum has been observed in chick and rodents (Wingate and Hatten 1999; Machold and Fishell 2005; Wang et al. 2005). Furthermore, in mouse, the first group of cells derived from ato1-expressing cells in the URL migrates rostroventrally and exits the cerebellum to form several different nuclei in the tegmentum (Wingate and Hatten 1999; Machold and Fishell 2005; Wang et al. 2005). In summary, the early generation of cells from the URL and their migratory pattern seems to be highly conserved in vertebrates.

Generation of cerebellar neurons starts $\sim 2$ days after fertilization in zebrafish. Initiation of layer formation starts at 3 days after fertilization when the first differentiated Purkinje cells are detected by the expression of markers such as Parvalbumin7, aldocl, rora2, coe2, and gad1-2 (Jaszai et al. 2003; Katsuyama et al. 2007; Volkmann et al. 2008; Bae et al. 2009; Elsen et al. 2009). It was recently shown that hepatocyte 
Adult Neurogenesis in Fish

growth factor signaling through its tyrosine kinase receptor Met is necessary for cerebellar proliferation, VZ progenitors, and subsequent Purkinje cell development (Elsen et al. 2009). Little is known about the development and specification of other inhibitory neuron types. Granule cell production starts 2 days after fertilization when granule cell precursors leave the URL. They rapidly migrate over a long distance and start to differentiate (Koster and Fraser 2001; Volkmann et al. 2008). The differentiating granule cells express atoh1a-c, zic1, zic2, zic3, reelin, pax6a, tag1, and neuroD1 (Koster and Fraser 2001; Costagli et al. 2002; Jaszai et al. 2003; Adolf et al. 2004; Toyama et al. 2004; Foucher et al. 2006; Aldinger and Elsen 2008; Volkmann et al. 2008; Bae et al. 2009; Chaplin et al. 2010). The granule cells migrate in chainlike structures from the URL. Cadherin-2 is necessary to mediate chain formation and coordinate migratory behaviors of granule cells (Rieger et al. 2009). Granule cells expressing mature markers, such as gabra6b and vglut1-2, are detected beneath the Purkinje cells 5 days after fertilization (Volkmann et al. 2008; Bae et al. 2009). Furthermore, all three cortical layers can be distinguished 5 days after fertilization. The transcription factor olig2 labels progenitors, mature oligodendrocytes, and eurydendroid cells in zebrafish (McFarland et al. 2008; Bae et al. 2009). During development, the eurydendroid cells are derived from olig2:gfp-expressing progenitors located in the caudal VZ and lateral regions of the URL. Interestingly, the olig2:gfpexpressing eurydendroid cells appear to be derived from both ptfla- and atoh1-expressing progenitors, although they are later excitatory in nature (Kani et al. 2010). Furthermore, antagonistic interplay between Hedgehog ( $\mathrm{Hh}$ ) and Wnt signaling regulates the number and distribution of olig2:gfp-expressing cells in the developing cerebellum. The absence of Hh signaling during early development increases the size of the olig2:gfp-expressing cell population, whereas Wnt signaling is necessary for the development of the olig2:gfp cells (McFarland et al. 2008). It has been proposed that Hh signaling may limit the range of Wnt signaling in the RL, which is necessary for the development of Olig2-expressing neurons (McFarland et al. 2008).

\section{Adult Cerebellar Neurogenesis}

Cerebellar progenitor activity and neurogenesis continue into adulthood in zebrafish (Grandel et al. 2006; Kaslin et al. 2009, 2013). Notable progenitor activity is detected along the fourth ventricle and its dorsomedial and lateral outpockets, the cerebellar recessus. Interestingly, the neural progenitors persist in a specialized niche in the adult zebrafish cerebellum (Fig. 5). Label-retaining, distinctly polarized neuroepithelial-like cells that express the neural stem cell and progenitor markers nestin, Sox2, Meis, and Musashil are found along the fourth ventricle and its dorsomedial and lateral out-pockets, the cerebellar recessus (Kaslin et al. 2009, 2013). Interestingly, the nestin-positive progenitors do not express radial or astroglial markers such as S100b, GFAP, vimentin, BLBP, GS, or Aro-B (Kaslin et al. 2009). The cerebellar stem-cell niche consists of polarized neuroepithelial-like progenitors that inhabit the dorsal part of the cerebellar recessus, whereas S100b and GFAP-expressing epithelial-like glia line the ventral part of the recessus (Fig. 5). Additionally, the neuroepithelial-like progenitors are flanked medially by radial glia and laterally by Bergmann glia. The neuroepithelial-like progenitors give rise to a population of dividing intermediate progenitors. The neuroepitheliallike cells and the intermediate progenitors express characteristic upper RL and granule cell markers such as atoh1c, zic1, zic3, reelin, neurod, Pax6, Meis1, and GAP-43 (Costagli et al. 2002; Kaslin et al. 2009; Chaplin et al. 2010; Kani et al. 2010). The intermediate progenitors rapidly migrate in a distinct outside-in fashion into the granule cell layer, in which they differentiate into granule cells. In the adult cerebellum, the granule precursors migrate into the granule cell layer within 3 days (Kaslin et al. 2009). Although several subtypes of inhibitory and excitatory cells are found in the zebrafish cerebellum, mainly granule cells are produced in the adult. In vivo imaging of the cerebellar stem cell niche from embryonic to adult stages showed that the 
niche is generated in a two-step process, that initially involves morphogenetic movements, and later, tissue growth. Because of these processes, RL progenitors and a small portion of the ventricle, the cerebellar recessus, are displaced deep into the cerebellar tissue (Kaslin et al. 2009, 2013). In contrast, the cerebellar midline and the ventricle are lost as the two cerebellar hemispheres fuse in chick and rodents (Altman and Bayer 1997; Louvi et al. 2003; Sgaier et al. 2005). Upper RL progenitors are maintained dorsal to the cerebellar recessus in the adult zebrafish, whereas VZ-derived progenitors and glia are found ventral to the recessus. The VZ-derived progenitors are almost quiescent in the adult zebrafish, which is consistent with the notion that few inhibitory neurons and glia are produced in the adult.

During development of amniotes, granule cell precursors migrate from the URL to the cerebellar surface, where they transiently form a highly proliferative second germinal zone, the EGL. Sonic hedgehog secreted from Purkinje neurons acts as the major mitogenic signal for granule precursors in the EGL (Dahmane and Ruiz i Altaba 1999; Wechsler-Reya and Scott 1999). In contrast to amniotes, Sonic hedgehog signaling and a prominent external granule cell layer is lacking in the developing and adult zebrafish cerebellum (Kaslin et al. 2009, 2013; Chaplin et al. 2010). Interestingly, the advent of a secondary zone of transient amplification (e.g., the external granule cell layer) seems to be an amniote-specific developmental adaptation, because shark, teleost fish and frogs lack an obvious external granule cell layer (Gona 1976; Chaplin et al. 2010). However, dividing intermediate granule precursors can be continuously detected in the zebrafish cerebellum, although the amplification rate is very low (Kaslin et al. 2009). This suggests that the production of granule cells in zebrafish is more likely to be controlled on the level of the primary progenitors (Kaslin et al. 2009). Not much is known about signals that control the proliferation and differentiation of the cerebellar progenitors in the adult zebrafish. However, fibroblast growth factor (Fgf) signaling is required for the maintenance and proliferation of the adult cerebellar progenitors (see below) (Kaslin et al. 2009). In addition, sex differences in proliferation have been detected in the adult cerebellum (Ampatzis and Dermon 2007).

\section{REGULATION OF ADULT NEUROGENESIS IN FISH}

Cell proliferation, progenitor self-renewal, and quiescence, as well as the generation of new neurons and glial cells, generally have to be carefully balanced and regulated in the adult brain. Different signaling pathways as well as environmental components have been shown to regulate proliferation and neurogenesis in fish. In the following, we will discuss different signaling pathways and environmental influences that have been shown to regulate progenitor proliferation and neurogenesis in the adult brain.

\section{Fibroblast Growth Factor Signaling}

The role of Fgf signaling in controlling adult progenitor proliferation has been analyzed in detail both in the telencephalon and cerebellum (Kaslin et al. 2009; Ganz et al. 2010). In the telencephalon, blockade of Fgf signaling significantly reduced the number of proliferating cells in $\mathrm{Vv}$, but not in Vd or in the dorsal telencephalon (Ganz et al. 2010). Interestingly, ectopic activation of Fgf signaling increased proliferation both in the ventral and the dorsal telencephalon (Ganz et al. 2010). Analysis of Fgf signaling components showed differential expression of Fgf receptors and downstream targets in the telencephalic progenitor zones (Topp et al. 2008; Ganz et al. 2010). One possibility for the different responses of the progenitor zone of $\mathrm{Vd}$ and the dorsal telencephalon to blockade of Fgf signaling compared with $\mathrm{Vv}$ is that only a subset of dorsal progenitors responds to Fgf signaling. Additional markers for subsets of progenitors will be necessary to resolve this issue. Alternatively, different proximity to an Fgf source could explain the differential response, because expression of $f g f 8 a$ and $f g f 3$ is restricted to the ventral part of $\mathrm{Vv}$, and $f g f 8 b$ is present only along the midline of the telencephalon (Topp et al. 2008; Ganz et al. 2010). This is reminiscent of embryonic development, in which 
the ventral telencephalon depends on Fgf3 and Fgf8a signaling (Shanmugalingam et al. 2000; Furthauer et al. 2001). Thus, progenitors in the ventral telencephalon might require higher levels of Fgf pathway activation from embryonic development into adulthood. In summary, Fgf signaling is required to directly regulate proliferation of telencephalic progenitors.

In the cerebellum, blockade of Fgf signaling leads to a significant reduction in the number of proliferating cells both in the stem cell niche and in the population of proliferating granule precursors (Kaslin et al. 2009). Different Fgfs ( $f g f 3$, $f g f 8 a$, and $f g f 8 b$ ) are expressed in the cerebellum in close proximity to the ventricle, but not directly in the stem cell niche (Topp et al. 2008). Two Fgf receptors ( $f g f r 2$ and $f g f r 3$ ) are present in the stem cell niche, which could mediate Fgf signals (Kaslin et al. 2009). However, high levels of Fgf activity are not present in the stem cell niche, but primarily in glia and granule cells (Kaslin et al. 2009). Fgf signaling is important in the cerebellum in regulating proliferation and Fgfs might propagate through the cerebellar ventricle to the stem cell niche.

\section{Notch Signaling}

In the telencephalon, Notch signaling has shown to play a role in controlling proliferation and adult neurogenesis in the zebrafish. Blocking Notch signaling in the dorsal telencephalon resulted in an increase in proliferation by switching quiescent radial glia to actively cycling glial cells (Chapouton et al. 2010). Conversely, by ectopically activating Notch signaling, progenitors exit the cell cycle, suggesting that Notch signaling might control the switch between quiescent and actively cycling glial marker positive progenitors in the dorsal telencephalon (Chapouton et al. 2010). This switch is at least partially mediated by notch3, as blocking notch3 expression in the dorsal telencephalon by electroporation of a notch3-morpholino leads to an increase in cycling radial glia cells (Alunni et al. 2013). The increase in proliferation after blocking Notch signaling also resulted in a net increase in number of neurons generated (Chapouton et al. 2010). Interestingly, not all quies- cent radial glia cells entered the cell cycle after Notch signaling blockade, which suggests that there are additional signaling pathways that maintain the balance between quiescence and proliferation in the dorsal telencephalon (Chapouton et al. 2010). Notch signaling pathway components are also differentially expressed in the ventral telencephalon as well as in the hypothalamus, optic tectum, and cerebellum (Chapouton et al. 2011; de Oliveira-Carlos et al. 2013). It will be interesting to determine whether Notch signaling plays a similar role in the ventral as in the dorsal telencephalon. Furthermore, elucidating the role Notch signaling plays in the different neurogenic niches in the adult zebrafish brain will be important to further understand the regulation of adult neurogenesis in fish.

\section{ENVIRONMENTAL INFLUENCE ON ADULT NEUROGENESIS}

In several teleost species, different environmental parameters, such as social interactions, stress, rearing conditions, and environmental complexity have been suggested to influence cell proliferation and neurogenesis in different brain regions in the adult (Lema et al. 2005; Dunlap et al. 2006, 2008, 2010, 2011a,b, 2013; Sorensen et al. 2007, 2011, 2012; Ampatzis et al. 2012; Maruska et al. 2012; Dunlap and Chung 2013) In the weakly electric fish A. leptorhynchus, social interactions of pairing two fish in an aquarium or hearing the electrocommunicating chirps from another individual increased the addition of cells specifically in the diencephalic prepacemaker nucleus (PPn) responsible for the electrocommunication behavior, and not in adjacent nuclei compared with isolated fish (Dunlap et al. 2008). Interestingly, exposing fish to a series of seven novel partners increased the addition of cells to the PPn compared with fish that were only exposed to two novel partners, suggesting that not only presence of social novelty increases cell addition, but sequential novel social stimuli might increase cell addition even more (Dunlap and Chung 2013). This increase in cells might be regulated by cortisol, because treatment with exogenous cortisol increased cell 
addition in PPn, whereas blocking glucocorticoid receptors inhibited cell addition in PPn (Dunlap et al. 2013). However, other factors must play a role in regulating the addition of cells, as blocking glucocorticoid receptors reduced cell addition only to about half of the isolated controls (Dunlap et al. 2013). Similarly, in the cichlid Astatotilapia burtoni, the social status influences the amount of proliferation in different brain regions (Maruska et al. 2012). Subordinate males show a significantly lower number of proliferating cells in analyzed brain regions (ventral telencephalon, POA, NRL, CP, TPp, and Ce) compared with dominant and ascending males. The latter also have significantly less proliferating cells than dominant males (Maruska et al. 2012). This increase in proliferation happens very rapidly as changes in proliferation could already be detected $24 \mathrm{~h}$ after the first display of dominance behavior in the ascending male (Maruska et al. 2012). Similarly, social stress reduced proliferation in the telencephalon of the rainbow trout Onchoryhnchus mykiss (Sorensen et al. 2011). Interestingly, in contrast to the results in the PPn of A. leptorhynchus, cortisol reduces cell proliferation in this system (Sorensen et al. 2011), suggesting that cortisol can have a differential influence on regulating adult neurogenesis in fish.

\section{FROM THE ZERBAFISH MODEL TO HUMAN DISEASE}

Adult neurogenesis is generally a conserved trait of all vertebrates studied. Comprehending the different modes of adult neurogenesis among different species should allow the identification of evolutionary conserved and derived characteristics of adult vertebrate neurogenesis. With more than 26,000 species, teleosts are the most species-rich group of vertebrates, with a great diversity of adult brain morphologies, habitats, and social behavior (Fig. 1) (Nieuwenhuys et al. 1998). Thus, analyzing adult neurogenesis in teleosts provides many different examples to determine which aspects and characteristics of adult neurogenesis are conserved among vertebrates. On the other hand, species-specific differences in proliferation or neurogenesis will al- low us also to learn more about different modes of adult neurogenesis and how they are regulated. This will help us comprehend which molecular mechanisms regulate vertebrate neurogenesis in general. A key challenge of biomedical interest will be to understand which differences in proliferation and regenerative capacities exist between the adult brains of teleosts and mammals. Key questions are, for example, which cell types in fish are homologous to which cell types in mammals? How comparable are their respective development and functions in teleost vs. mammalian brains? Which genetic mechanisms drive these cell populations in fish, and are they comparable to mammalian mechanisms? How is the seemingly unique teleost ability to regenerate its brain neurons and glia encoded, and can one reactivate such mechanisms in the mammalian brain? Answers to some of these questions are beginning to emerge, but will they reveal new strategies for treating neurodegenerative disease, stroke, and traumatic brain injuries in man? In concert with modern genetic, genomic and neurobiological technologies, answers to some of these fascinating questions can be expected. Conceivably, understanding how adult neurogenesis and especially the generation of specific neuronal subtypes is regulated in teleosts, with zebrafish as a "workhorse representative," might eventually inform therapeutic approaches to replace lost neurons under conditions of human brain injury and neurodegenerative disease.

\section{ACKNOWLEDGMENTS}

This work is supported by the European Union (Zf Health), the Deutsche Forschungsgemeinschaft (SFB 655 A3), and a CRTD seed grant to M.B. J.G. was supported by a postdoctoral research fellowship from the German Research foundation (DFG). We thank the past and present members of the Brand Laboratory for discussions, and Ingo Braasch for help with preparing Figure 1.

\section{REFERENCES}

Adolf B, Bellipanni G, Huber V, Bally-Cuif L. 2004. atoh1.2 and beta3.1 are two new bHLH-encoding genes expressed 
in selective precursor cells of the zebrafish anterior hindbrain. Gene Expr Patterns 5: 35-41.

Adolf B, Chapouton P, Lam CS, Topp S, Tannhauser B, Strahle U, Gotz M, Bally-Cuif L. 2006. Conserved and acquired features of adult neurogenesis in the zebrafish telencephalon. Dev Biol 295: 278-293.

Aldinger KA, Elsen GE. 2008. Ptfla is a molecular determinant for both glutamatergic and GABAergic neurons in the hindbrain. J Neurosci 28: 338-339.

Altman J, Bayer SA. 1997. Development of the cerebellar system: In relation to its evolution, structure, and functions. CRC, Boca Raton, FL.

Alunni A, Hermel JM, Heuze A, Bourrat F, Jamen F, Joly JS. 2010. Evidence for neural stem cells in the medaka optic tectum proliferation zones. Dev Neurobiol 70: 693-713.

Alunni A, Krecsmarik M, Bosco A, Galant S, Pan L, Moens CB, Bally-Cuif L. 2013. Notch3 signaling gates cell cycle entry and limits neural stem cell amplification in the adult pallium. Development 140: 3335-3347.

Alvarez-Buylla A, Kohwi M, Nguyen TM, Merkle FT. 2008. The heterogeneity of adult neural stem cells and the emerging complexity of their niche. Cold Spring Harb Symp Quant Biol 73: 357-365.

Ampatzis K, Dermon CR. 2007. Sex differences in adult cell proliferation within the zebrafish (Danio rerio) cerebellum. Eur J Neurosci 25: 1030-1040.

Ampatzis K, Makantasi P, Dermon CR. 2012. Cell proliferation pattern in adult zebrafish forebrain is sexually dimorphic. Neuroscience 226: 367-381.

Bae YK, Kani S, Shimizu T, Tanabe K, Nojima H, Kimura Y, Higashijima S, Hibi M. 2009. Anatomy of zebrafish cerebellum and screen for mutations affecting its development. Dev Biol 330: 406-426.

Becker CG, Becker T. 2015. Neuronal regeneration from ependymo-radial glial cells: Cook, little pot, cook! Dev Cell 32: 516-527.

Ben-Arie N, Bellen HJ, Armstrong DL, McCall AE, Gordadze PR, Guo Q, Matzuk MM, Zoghbi HY. 1997. Math1 is essential for genesis of cerebellar granule neurons. Nature 390: 169-172.

Brandstätter R, Kotrschal K. 1989. Life history of roach, Rutilus rutilus (Cyprinidae, Teleostei). A qualitative and quantitative study on the development of sensory brain areas. Brain Behav Evol 34: 35-42.

Brandstätter R, Kotrschal K. 1990. Brain growth patterns in four European cyprinid fish species (Cyprinidae, Teleostei): Roach (Rutilus rutilus), bream (Abramis brama), common carp (Cyprinus carpio) and sabre carp (Pelecus cultratus). Brain Behav Evol 35: 195-201.

Broglio C, Rodriguez F, Gomez A, Arias JL, Salas C. 2010. Selective involvement of the goldfish lateral pallium in spatial memory. Behav Brain Res 210: 191-201.

Candal E, Anadon R, DeGrip WJ, Rodriguez-Moldes I. 2005. Patterns of cell proliferation and cell death in the developing retina and optic tectum of the brown trout. Brain Res Dev Brain Res 154: 101-119.

Carletti B, Rossi F. 2008. Neurogenesis in the cerebellum. Neuroscientist 14: 91-100.

Chaplin N, Tendeng C, Wingate RJ. 2010. Absence of an external germinal layer in zebrafish and shark reveals a distinct, anamniote ground plan of cerebellum development. J Neurosci 30: 3048-3057.

Chapouton P, Skupien P, Hesl B, Coolen M, Moore JC, Madelaine R, Kremmer E, Faus-Kessler T, Blader P, Lawson ND, et al. 2010. Notch activity levels control the balance between quiescence and recruitment of adult neural stem cells. J Neurosci 30: 7961-7974.

Chapouton P, Webb KJ, Stigloher C, Alunni A, Adolf B, Hesl B, Topp S, Kremmer E, Bally-Cuif L. 2011. Expression of hairy/enhancer of split genes in neural progenitors and neurogenesis domains of the adult zebrafish brain. $J$ Comp Neurol 519: 1748-1769.

Costagli A, Kapsimali M, Wilson SW, Mione M. 2002. Conserved and divergent patterns of Reelin expression in the zebrafish central nervous system. J Comp Neurol 450: 73-93.

Dahmane N, Ruiz i Altaba A. 1999. Sonic hedgehog regulates the growth and patterning of the cerebellum. Development 126: 3089-3100.

de Oliveira-Carlos V, Ganz J, Hans S, Kaslin J, Brand M. 2013. Notch receptor expression in neurogenic regions of the adult zebrafish brain. PLoS ONE 8: e73384.

Dunlap KD, Chung M. 2013. Social novelty enhances brain cell proliferation, cell survival, and chirp production in an electric fish, Apteronotus leptorhynchus. Dev Neurobiol 73: $324-332$.

Dunlap KD, Castellano JF, Prendaj E. 2006. Social interaction and cortisol treatment increase cell addition and radial glia fiber density in the diencephalic periventricular zone of adult electric fish, Apteronotus leptorhynchus. Horm Behav 50: 10-17.

Dunlap KD, McCarthy EA, Jashari D. 2008. Electrocommunication signals alone are sufficient to increase neurogenesis in the brain of adult electric fish, Apteronotus leptorhynchus. Dev Neurobiol 68: 1420-1428.

Dunlap KD, DiBenedictis BT, Banever SR. 2010. Chirping response of weakly electric knife fish (Apteronotus leptorhynchus) to low-frequency electric signals and to heterospecific electric fish. J Exp Biol 213: 2234-2242.

Dunlap KD, Jashari D, Pappas KM. 2011a. Glucocorticoid receptor blockade inhibits brain cell addition and aggressive signaling in electric fish, Apteronotus leptorhynchus. Horm Behav 60: 275-283.

Dunlap KD, Silva AC, Chung M. 2011b. Environmental complexity, seasonality and brain cell proliferation in a weakly electric fish, Brachyhypopomus gauderio. J Exp Biol 214: 794-805.

Dunlap KD, Chung M, Castellano JF. 2013. Influence of long-term social interaction on chirping behavior, steroid levels and neurogenesis in weakly electric fish. $J$ Exp Biol 216: 2434-2441.

Duran E, Ocana FM, Broglio C, Rodriguez F, Salas C. 2010. Lateral but not medial telencephalic pallium ablation impairs the use of goldfish spatial allocentric strategies in a "hole-board" task. Behav Brain Res 214: 480-487.

Edelmann K, Glashauser L, Sprungala S, Hesl B, Fritschle M, Ninkovic J, Godinho L, Chapouton P. 2013. Increased radial glia quiescence, decreased reactivation upon injury and unaltered neuroblast behavior underlie decreased neurogenesis in the aging zebrafish telencephalon. $J$ Comp Neurol 521: 3099-3115. 
J. Ganz and M. Brand

Ekstrom P, Johnsson CM, Ohlin LM. 2001. Ventricular proliferation zones in the brain of an adult teleost fish and their relation to neuromeres and migration (secondary matrix) zones. J Comp Neurol 436: 92-110.

Elsen GE, Choi LY, Prince VE, Ho RK. 2009. The autism susceptibility gene met regulates zebrafish cerebellar development and facial motor neuron migration. Dev Biol 335: 78-92.

Englund C, Kowalczyk T, Daza RA, Dagan A, Lau C, Rose MF, Hevner RF. 2006. Unipolar brush cells of the cerebellum are produced in the rhombic lip and migrate through developing white matter. J Neurosci 26: 9184-9195.

Fernandez AS, Rosillo JC, Casanova G, Olivera-Bravo S. 2011. Proliferation zones in the brain of adult fish Austrolebias (Cyprinodontiform: Rivulidae): A comparative study. Neuroscience 189: 12-24.

Fink AJ, Englund C, Daza RA, Pham D, Lau C, Nivison M, Kowalczyk T, Hevner RF. 2006. Development of the deep cerebellar nuclei: Transcription factors and cell migration from the rhombic lip. J Neurosci 26: 3066-3076.

Flames N, Pla R, Gelman DM, Rubenstein JL, Puelles L, Marin O. 2007. Delineation of multiple subpallial progenitor domains by the combinatorial expression of transcriptional codes. J Neurosci 27: 9682-9695.

Folgueira M, Bayley P, Navratilova P, Becker TS, Wilson SW, Clarke JD. 2012. Morphogenesis underlying the development of the everted teleost telencephalon. Neural Dev 7: 32.

Foucher I, Mione M, Simeone A, Acampora D, Bally-Cuif L, Houart C. 2006. Differentiation of cerebellar cell identities in absence of Fgf signalling in zebrafish Otx morphants. Development 133: 1891-1900.

Furthauer M, Reifers F, Brand M, Thisse B, Thisse C. 2001. sprouty 4 acts in vivo as a feedback-induced antagonist of FGF signaling in zebrafish. Development 128: 2175-2186.

Ganz J, Kaslin J, Hochmann S, Freudenreich D, Brand M. 2010. Heterogeneity and Fgf dependence of adult neural progenitors in the zebrafish telencephalon. Glia 58: 1345-1363.

Ganz J, Kaslin J, Freudenreich D, Machate A, Geffarth M, Brand M. 2012. Subdivisions of the adult zebrafish subpallium by molecular marker analysis. J Comp Neurol 520: 633-655.

Ganz J, Kroehne V, Freudenreich D, Machate A, Geffarth M, Braasch I, Kaslin J, Brand M. 2014. Subdivisions of the adult zebrafish pallium based on molecular marker analysis. F1000Res 3: 308.

Gona AG. 1976. Autoradiographic studies of cerebellar histogenesis in the bullfrog tadpole during metamorphosis: The external granular layer. J Comp Neurol 165: 77-87.

Grandel H, Brand M. 2013. Comparative aspects of adult neural stem cell activity in vertebrates. Dev Genes Evol 223: $131-147$.

Grandel H, Kaslin J, Ganz J, Wenzel I, Brand M. 2006. Neural stem cells and neurogenesis in the adult zebrafish brain: Origin, proliferation dynamics, migration and cell fate. Dev Biol 295: 263-277.

Guillemot F. 2005. Cellular and molecular control of neurogenesis in the mammalian telencephalon. Curr Opin Cell Biol 17: 639-647.
Hans S, Kaslin J, Freudenreich D, Brand M. 2009. Temporally controlled site-specific recombination in zebrafish. PLOS ONE 4: e4640.

Hans S, Freudenreich D, Geffarth M, Kaslin J, Machate A, Brand M. 2011. Generation of a non-leaky heat shockinducible Cre line for conditional Cre/lox strategies in zebrafish. Dev Dyn 240: 108-115.

Hauptmann G, Soll I, Gerster T. 2002. The early embryonic zebrafish forebrain is subdivided into molecularly distinct transverse and longitudinal domains. Brain Res Bull 57: 371-375.

Hoshino M, Nakamura S, Mori K, Kawauchi T, Terao M, Nishimura YV, Fukuda A, Fuse T, Matsuo N, Sone M, et al. 2005. Ptfla, a bHLH transcriptional gene, defines GABAergic neuronal fates in cerebellum. Neuron 47: $201-$ 213.

Ito Y, Tanaka H, Okamoto H, Ohshima T. 2010. Characterization of neural stem cells and their progeny in the adult zebrafish optic tectum. Dev Biol 342: 26-38.

Jaszai J, Reifers F, Picker A, Langenberg T, Brand M. 2003. Isthmus-to-midbrain transformation in the absence of midbrain-hindbrain organizer activity. Development 130: 6611-6623.

Jungke P, Hans S, Brand M. 2013. The zebrafish CreZoo: An easy-to-handle database for novel $\mathrm{CreER}^{\mathrm{T} 2}$-driver lines. Zebrafish 10: 259-263.

Kani S, Bae YK, Shimizu T, Tanabe K, Satou C, Parsons MJ, Scott E, Higashijima S, Hibi M. 2010. Proneural genelinked neurogenesis in zebrafish cerebellum. Dev Biol 343: $1-17$.

Kaslin J, Brand M. 2012 Cerebellar development and neurogenesis in zebrafish. In Handbook of the cerebellum and cerebellar disorders (ed. Manto M, et al.). Springer, New York.

Kaslin J, Ganz J, Brand M. 2008. Proliferation, neurogenesis and regeneration in the non-mammalian vertebrate brain. Philos Trans R Soc Lond B Biol Sci 363: 101-122.

Kaslin J, Ganz J, Geffarth M, Grandel H, Hans S, Brand M. 2009. Stem cells in the adult zebrafish cerebellum: Initiation and maintenance of a novel stem cell niche. J Neurosci 29: 6142-6153.

Kaslin J, Kroehne V, Benato F, Argenton F, Brand M. 2013. Development and specification of cerebellar stem and progenitor cells in zebrafish: From embryo to adult. Neural Dev 8: 9.

Katsuyama Y, Oomiya Y, Dekimoto H, Motooka E, Takano A, Kikkawa S, Hibi M, Terashima T. 2007. Expression of zebrafish $R O R \alpha$ gene in cerebellar-like structures. Dev Dyn 236: 2694-2701.

Kim CH, Bae YK, Yamanaka Y, Yamashita S, Shimizu T, Fujii R, Park HC, Yeo SY, Huh TL, Hibi M, et al. 1997. Overexpression of neurogenin induces ectopic expression of $\mathrm{HuC}$ in zebrafish. Neurosci Lett 239: 113-116.

Kishimoto N, Alfaro-Cervello C, Shimizu K, Asakawa K, Urasaki A, Nonaka S, Kawakami K, Garcia-Verdugo JM, Sawamoto K. 2011. Migration of neuronal precursors from the telencephalic ventricular zone into the olfactory bulb in adult zebrafish. J Comp Neurol 519: 3549-3565.

Kizil C, Dudczig S, Kyritsis N, Machate A, Blaesche J, Kroehne V, Brand M. 2012a. The chemokine receptor 
cxcr5 regulates the regenerative neurogenesis response in the adult zebrafish brain. Neural Dev 7: 27.

Kizil C, Kaslin J, Kroehne V, Brand M. 2012b. Adult neurogenesis and brain regeneration in zebrafish. Dev Neurobiol 72: 429-461.

Kizil C, Kyritsis N, Dudczig S, Kroehne V, Freudenreich D, Kaslin J, Brand M. 2012c. Regenerative neurogenesis from neural progenitor cells requires injury-induced expression of Gata3. Dev Cell 23: 1230-1237.

Koster RW, Fraser SE. 2001. Direct imaging of in vivo neuronal migration in the developing cerebellum. Curr Biol 11: $1858-1863$.

Kroehne V, Brand M. 2012. The cellular basis of constitutive and regenerative neurogenesis in the adult zebrafish brain. Cell News 38: 12-16.

Kroehne V, Freudenreich D, Hans S, Kaslin J, Brand M. 2011. Regeneration of the adult zebrafish brain from neurogenic radial glia-type progenitors. Development 138: 4831 4841.

Kuroyanagi Y, Okuyama T, Suehiro Y, Imada H, Shimada A, Naruse K, Takeda H, Kubo T, Takeuchi H. 2010. Proliferation zones in adult medaka (Oryzias latipes) brain. Brain Res 1323: 33-40.

Kyritsis N, Kizil C, Zocher S, Kroehne V, Kaslin J, Freudenreich D, Iltzsche A, Brand M. 2012. Acute inflammation initiates the regenerative response in the adult zebrafish brain. Science 338: 1353-1356.

Kyritsis N, Kizil C, Brand M. 2014. Neuroinflammation and central nervous system regeneration in vertebrates. Trends Cell Biol 24: 128-135.

Lam CS, Marz M, Strahle U. 2009. gfap and nestin reporter lines reveal characteristics of neural progenitors in the adult zebrafish brain. Dev Dyns 238: 475-486.

Langenberg T, Dracz T, Oates AC, Heisenberg CP, Brand M. 2006. Analysis and visualization of cell movement in the developing zebrafish brain. Dev Dyn 235: 928-933.

Lema SC, Hodges MJ, Marchetti MP, Nevitt GA. 2005. Proliferation zones in the salmon telencephalon and evidence for environmental influence on proliferation rate. Comp Biochem Physiol A Mol Integr Physiol 141: 327-335.

Lindsey BW, Tropepe V. 2006. A comparative framework for understanding the biological principles of adult neurogenesis. Prog Neurobiol 80: 281-307.

Lindsey BW, Darabie A, Tropepe V. 2012. The cellular composition of neurogenic periventricular zones in the adult zebrafish forebrain. J Comp Neurol 520: 2275-2316.

Louvi A, Alexandre P, Metin C, Wurst W, Wassef M. 2003. The isthmic neuroepithelium is essential for cerebellar midline fusion. Development 130: 5319-5330.

Machold R, Fishell G. 2005. Math1 is expressed in temporally discrete pools of cerebellar rhombic-lip neural progenitors. Neuron 48: 17-24.

Maggi R, Zasso J, Conti L. 2014. Neurodevelopmental origin and adult neurogenesis of the neuroendocrine hypothalamus. Front Cell Neurosci 8: 440 .

Marcus RC, Delaney CL, Easter SS Jr. 1999. Neurogenesis in the visual system of embryonic and adult zebrafish (Danio rerio). Vis Neurosci 16: 417-424.

Maruska KP, Carpenter RE, Fernald RD. 2012. Characterization of cell proliferation throughout the brain of the African cichlid fish Astatotilapia burtoni and its regulation by social status. J Comp Neurol 520: 34713491.

Marz M, Chapouton P, Diotel N, Vaillant C, Hesl B, Takamiya M, Lam CS, Kah O, Bally-Cuif L, Strahle U. 2010a. Heterogeneity in progenitor cell subtypes in the ventricular zone of the zebrafish adult telencephalon. Glia 58: 870-888.

Marz M, Schmidt R, Rastegar S, Strahle U. 2010b. Expression of the transcription factor Olig2 in proliferating cells in the adult zebrafish telencephalon. Dev Dyn 239:33363349.

McFarland KA, Topczewska JM, Weidinger G, Dorsky RI, Appel B. 2008. Hh and Wnt signaling regulate formation of olig $2^{+}$neurons in the zebrafish cerebellum. Dev Biol 318: $162-171$.

Meek J. 1983. Functional anatomy of the tectum mesencephali of the goldfish. An explorative analysis of the functional implications of the laminar structural organization of the tectum. Brain Res 287: 247-297.

Menuet A, Pellegrini E, Brion F, Gueguen MM, Anglade I, Pakdel F, Kah O. 2005. Expression and estrogen-dependent regulation of the zebrafish brain aromatase gene. $J$ Comp Neurol 485: 304-320.

Mueller T, Guo S. 2009. The distribution of GAD67mRNA in the adult zebrafish (teleost) forebrain reveals a prosomeric pattern and suggests previously unidentified homologies to tetrapods. J Comp Neurol 516: 553-568.

Mueller T, Wullimann MF, Guo S. 2008. Early teleostean basal ganglia development visualized by zebrafish Dlx2a, Lhx6, Lhx7, Tbr2 (eomesa), and GAD67 gene expression. J Comp Neurol 507: 1245-1257.

Nguyen V, Deschet K, Henrich T, Godet E, Joly JS, Wittbrodt J, Chourrout D, Bourrat F. 1999. Morphogenesis of the optic tectum in the medaka (Oryzias latipes): A morphological and molecular study, with special emphasis on cell proliferation. J Comp Neurol 413: 385-404.

Nieuwenhuys R. 2009. The forebrain of actinopterygians revisited. Brain Behav Evol 73: 229-252.

Nieuwenhuys R, Meek J. 1990. The elencephalon of Actinopterygian fishes. Cereb Cortex 8A: 31-73.

Nieuwenhuys R, Donkelaar HJt, Nicholson C. 1998. The central nervous system of vertebrates. Springer, Berlin.

Northcutt RG. 1995. The forebrain of gnathostomes: In search of a morphotype. Brain Behav Evol 46: 275-318.

Olivera-Pasilio V, Peterson DA, Castello ME. 2014. Spatial distribution and cellular composition of adult brain proliferative zones in the teleost, Gymnotus omarorum. Front Neuroanat 8: 88

Pascual M, Abasolo I, Mingorance-Le Meur A, Martinez A, Del Rio JA, Wright CV, Real FX, Soriano E. 2007. Cerebellar GABAergic progenitors adopt an external granule cell-like phenotype in the absence of Ptfla transcription factor expression. Proc Natl Acad Sci 104: 5193-5198.

Pellegrini E, Mouriec K, Anglade I, Menuet A, Le Page Y, Gueguen MM, Marmignon MH, Brion F, Pakdel F, Kah O. 2007. Identification of aromatase-positive radial glial cells as progenitor cells in the ventricular layer of the forebrain in zebrafish. J Comp Neurol 501: $150-167$. 
J. Ganz and M. Brand

Puelles L, Kuwana E, Puelles E, Bulfone A, Shimamura K, Keleher J, Smiga S, Rubenstein JL. 2000. Pallial and subpallial derivatives in the embryonic chick and mouse telencephalon, traced by the expression of the genes Dlx-2, Emx-1, Nkx-2.1, Pax-6, and Tbr-1. J Comp Neurol 424: 409-438.

Raymond PA, Easter SS Jr. 1983. Postembryonic growth of the optic tectum in goldfish. I: Location of germinal cells and numbers of neurons produced. J Neurosci 3: 10771091.

Raymond PA, Easter SS Jr, Burnham JA, Powers MK. 1983. Postembryonic growth of the optic tectum in goldfish. II: Modulation of cell proliferation by retinal fiber input. $J$ Neurosci 3: 1092-1099.

Rhinn M, Lun K, Luz M, Werner M, Brand M. 2005. Positioning of the midbrain-hindbrain boundary organizer through global posteriorization of the neuroectoderm mediated by Wnt8 signaling. Dev Biol 132: 1261-1272.

Rieger S, Senghaas N, Walch A, Koster RW. 2009. Cadherin2 controls directional chain migration of cerebellar granule neurons. PLoS Biol 7: e1000240.

Rodriguez F, Lopez JC, Vargas JP, Broglio C, Gomez Y, Salas C. 2002a. Spatial memory and hippocampal pallium through vertebrate evolution: Insights from reptiles and teleost fish. Brain Res Bull 57: 499-503.

Rodriguez F, Lopez JC, Vargas JP, Gomez Y, Broglio C, Salas C. 2002b. Conservation of spatial memory function in the pallial forebrain of reptiles and ray-finned fishes. $J$ Neurosci 22: 2894-2903.

Rojczyk-Golebiewska E, Palasz A, Wiaderkiewicz R. 2014. Hypothalamic subependymal niche: A novel site of the adult neurogenesis. Cell Mol Neurobiol 34: 631-642.

Rothenaigner I, Krecsmarik M, Hayes JA, Bahn B, Lepier A, Fortin G, Gotz M, Jagasia R, Bally-Cuif L. 2011. Clonal analysis by distinct viral vectors identifies bona fide neural stem cells in the adult zebrafish telencephalon and characterizes their division properties and fate. Development 138: 1459-1469.

Sgaier SK, Millet S, Villanueva MP, Berenshteyn F, Song C, Joyner AL. 2005. Morphogenetic and cellular movements that shape the mouse cerebellum; insights from genetic fate mapping. Neuron 45: 27-40.

Sgaier SK, Lao Z, Villanueva MP, Berenshteyn F, Stephen D, Turnbull RK, Joyner AL. 2007. Genetic subdivision of the tectum and cerebellum into functionally related regions based on differential sensitivity to engrailed proteins. Development 134: 2325-2335.

Shanmugalingam S, Houart C, Picker A, Reifers F, Macdonald R, Barth A, Griffin K, Brand M, Wilson SW. 2000. Ace/Fgf8 is required for forebrain commissure formation and patterning of the telencephalon. Development 127: 2549-2561.

Sorensen C, Overli O, Summers CH, Nilsson GE. 2007. Social regulation of neurogenesis in teleosts. Brain Behav Evol 70: 239-246.

Sorensen C, Bohlin LC, Overli O, Nilsson GE. 2011. Cortisol reduces cell proliferation in the telencephalon of rainbow trout (Oncorhynchus mykiss). Physiol Behav 102: 518523.

Sorensen C, Nilsson GE, Summers CH, Overli O. 2012. Social stress reduces forebrain cell proliferation in rain- bow trout (Oncorhynchus mykiss). Behav Brain Res 227: 311-318.

Stevenson JA, Yoon MG. 1981. Mitosis of radial glial cells in the optic tectum of adult goldfish. J Neurosci 1: 862-875.

Strobl-Mazzulla PH, Nunez A, Pellegrini E, Gueguen MM, Kah O, Somoza GM. 2010. Progenitor radial cells and neurogenesis in pejerrey fish forebrain. Brain Behav Evol 76: 20-31.

Teles MC, Sirbulescu RF, Wellbrock UM, Oliveira RF, Zupanc GK. 2012. Adult neurogenesis in the brain of the Mozambique tilapia, Oreochromis mossambicus. J Comp Physiol A Neuroethol Sens Neural Behav Physiol 198: 427449.

Topp S, Stigloher C, Komisarczuk AZ, Adolf B, Becker TS, Bally-Cuif L. 2008. Fgf signaling in the zebrafish adult brain: Association of Fgf activity with ventricular zones but not cell proliferation. J Comp Neurol 510: 422-439.

Toyama R, Gomez DM, Mana MD, Dawid IB. 2004. Sequence relationships and expression patterns of zebrafish zic2 and zic5 genes. Gene Expr Patterns 4: 345-350.

Tozzini ET, Baumgart M, Battistoni G, Cellerino A. 2012. Adult neurogenesis in the short-lived teleost Nothobranchius furzeri: Localization of neurogenic niches, molecular characterization and effects of aging. Aging Cell 11: 241-251.

Traniello IM, Sirbulescu RF, Ilies I, Zupanc GK. 2014. Agerelated changes in stem cell dynamics, neurogenesis, apoptosis, and gliosis in the adult brain: A novel teleost fish model of negligible senescence. Dev Neurobiol 74: 514530 .

Volkmann K, Rieger S, Babaryka A, Koster RW. 2008. The zebrafish cerebellar rhombic lip is spatially patterned in producing granule cell populations of different functional compartments. Dev Biol 313: 167-180.

Volkmann K, Chen YY, Harris MP, Wullimann MF, Koster RW. 2010. The zebrafish cerebellar upper rhombic lip generates tegmental hindbrain nuclei by long-distance migration in an evolutionary conserved manner. $J$ Comp Neurol 518: 2794-2817.

Wang VY, Zoghbi HY. 2001. Genetic regulation of cerebellar development. Nat Rev Neurosci 2: 484-491.

Wang VY, Rose MF, Zoghbi HY. 2005. Math1 expression redefines the rhombic lip derivatives and reveals novel lineages within the brainstem and cerebellum. Neuron 48: $31-43$.

Wechsler-Reya RJ, Scott MP. 1999. Control of neuronal precursor proliferation in the cerebellum by Sonic hedgehog. Neuron 22: 103-114.

Wingate RJ. 2001. The rhombic lip and early cerebellar development. Curr Opin Neurobiol 11: 82-88.

Wingate RJ, Hatten ME. 1999. The role of the rhombic lip in avian cerebellum development. Development 126: 4395 4404.

Wullimann MF, Rupp B, Reichert H. 1996. Neuroanatomy of the zebrafish brain: A topological atlas. Birkhauser Verlag, Boston.

Zecchin E, Mavropoulos A, Devos N, Filippi A, Tiso N, Meyer D, Peers B, Bortolussi M, Argenton F. 2004. Evolutionary conserved role of ptfla in the specification of exocrine pancreatic fates. Dev Biol 268: 174184. 
Zerucha T, Ekker M. 2000. Distal-less-related homeobox genes of vertebrates: Evolution, function, and regulation. Biochem Cell Biol 78: 593-601.

Zikopoulos B, Kentouri M, Dermon CR. 2000. Proliferation zones in the adult brain of a sequential hermaphrodite teleost species (Sparus aurata). Brain Behav Evol 56: $310-322$.
Zupanc GK, Horschke I. 1995. Proliferation zones in the brain of adult gymnotiform fish: A quantitative mapping study. J Comp Neurol 353: 213-233.

Zupanc GK, Hinsch K, Gage FH. 2005. Proliferation, migration, neuronal differentiation, and long-term survival of new cells in the adult zebrafish brain. J Comp Neurol 488: $290-319$. 


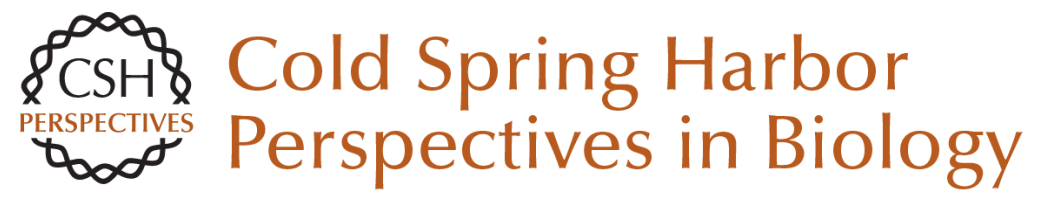

\section{Adult Neurogenesis in Fish}

Julia Ganz and Michael Brand

Cold Spring Harb Perspect Biol 2016; doi: 10.1101/cshperspect.a019018 originally published online January 8, 2016

\section{Subject Collection Neurogenesis}

Adult Neurogenesis and Psychiatric Disorders Eunchai Kang, Zhexing Wen, Hongjun Song, et al.

Neuronal Circuitry Mechanisms Regulating Adult Mammalian Neurogenesis Juan Song, Reid H.J. Olsen, Jiaqi Sun, et al.

Neurogenesis in the Developing and Adult Brain

--Similarities and Key Differences

Magdalena Götz, Masato Nakafuku and David Petrik

Genetics and Epigenetics in Adult Neurogenesis Jenny Hsieh and Xinyu Zhao

The Adult Ventricular-Subventricular Zone (V-SVZ) and Olfactory Bulb (OB) Neurogenesis Daniel A. Lim and Arturo Alvarez-Buylla

Diversity of Neural Precursors in the Adult Mammalian Brain Michael A. Bonaguidi, Ryan P. Stadel, Daniel A. Berg, et al.

Detection and Phenotypic Characterization of Adult Neurogenesis $H$. Georg Kuhn, Amelia J. Eisch, Kirsty Spalding, et al.

Maturation and Functional Integration of New Granule Cells into the Adult Hippocampus Nicolas Toni and Alejandro F. Schinder
Adult Olfactory Bulb Neurogenesis

Pierre-Marie Lledo and Matt Valley

Adult Neurogenesis in Fish Julia Ganz and Michael Brand

In Vitro Models for Neurogenesis Hassan Azari and Brent A. Reynolds

Engineering of Adult Neurogenesis and Gliogenesis

Benedikt Berninger and Sebastian Jessberger

Computational Modeling of Adult Neurogenesis James B. Aimone

Control of Adult Neurogenesis by Short-Range Morphogenic-Signaling Molecules Youngshik Choe, Samuel J. Pleasure and Helena Mira

Adult Neurogenesis: An Evolutionary Perspective Gerd Kempermann

Epilepsy and Adult Neurogenesis

Sebastian Jessberger and Jack M. Parent

For additional articles in this collection, see http://cshperspectives.cshlp.org/cgi/collection/

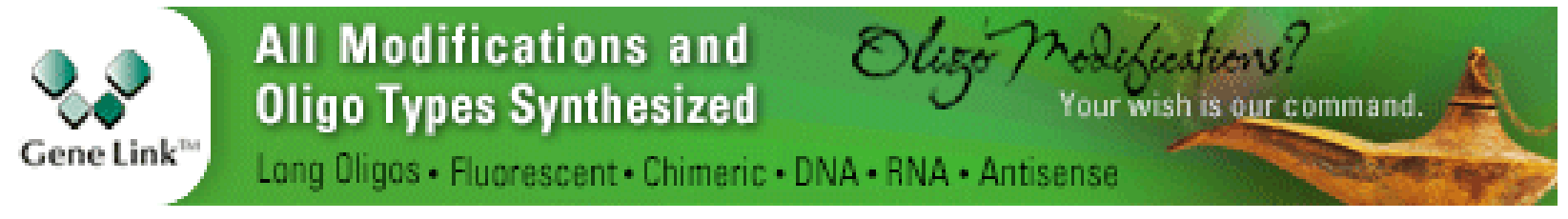


For additional articles in this collection, see http://cshperspectives.cshlp.org/cgi/collection/

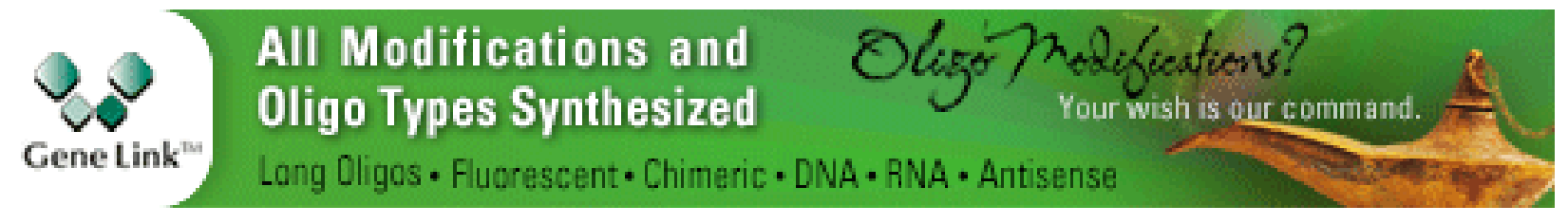

Copyright @ 2016 Cold Spring Harbor Laboratory Press; all rights reserved 